\title{
Evolución del empleo en México: 1895-1980*
}

\author{
Teresa Rendón y Carlos Salas**
}

\begin{abstract}
En este artículo se analizan las transformaciones que sufrieron en México, entre 1895 y 1980, tanto el nivel de ocupación como su estructura por sectores económicos. La base principal del trabajo son las cifras sobre ocupación que aparecen en los censos de población, previamente homogeneizadas por los autores. Además de señalar las tendencias de largo plazo en el empleo global y sectorial, el estudio muestra la existencia de tres periodos en la evolución del empleo. El primero (1895-1930), abarca el fin del auge asociado al proceso de acumulación sustentado en la exportación de metales y de determinados productos agricolas, así como una prolongada etapa de estancamiento económico correspondiente a la crisis de ese estadio del desarrollo del pás. El segundo periodo (1930-1970), cubre la fase expansiva del ciclo asociado a un patrón de acumulación que tiene como eje al sector manufacturero orientado al mercado interno; all se distinguen dos etapas: de 1930 a 1950 ocurre la transición de un patrón a otro; y de 1950 a 1970, se consolida el desarrollo industrial. Por último, en el decenio de los setenta el proceso de desarrollo se encuentra con serios obstáculos para continuar. En cada uno de estos periodos, la ocupación adquiere caracteristicas distintivas en lo que respecta a su ritmo de crecimiento y a su estructura por ramas de actividad. $A$ lo largo del texto se muestra la existencia de tendencias de largo plazo, manifiestas tanto en los cambios en el volumen como en la composición del empleo; asimismo, se plantea una serie de interrogantes respecto a las causas de algunas de las transformaciones en la ocupación que pueden observarse durante el periodo estudiado.
\end{abstract}

\section{Introducción}

Uno de los aspectos menos estudiados de la historia económica de nuestro país es la ocupación. ${ }^{1}$ Esto es fácilmente explicable puesto que las fuentes estadísticas, además de ser escasas, presentan múltiples dificultades para su análisis sistemático. En un intento por avanzar en el conocimiento de los nexos entre la transformación de la estructura productiva y los cambios en la ocupación, nos dimos a la tarea de realizar este trabajo. Tomando como base los censos de población levantados entre 1895 y 1980, construimos series históricas de ocupación, según criterios que permiten la mayor comparabilidad intercensal posible. ${ }^{2}$ En el cuadro 1 se

\footnotetext{
* Una versión preliminar de este trabajo fue presentada en el Centro de Estudios MéxicoEstados Unidos de la Universidad de California en San Diego en mayo de 1985. Posteriormente este material se ha discutido en el seminario del área "Acumulación y crisis en México" de la División de Estudios de Posgrado de la Facultad de Fconomía de la UNAM. Los autores agradecen, en especial, los comentarios de los participantes en dicho seminario.

** División de Estudios de Posgrado, Facultad de Economía, UNAM.

${ }^{1}$ Una excepción serian los trabajos de Keesing (1969 y 1977).

${ }^{2}$ Los detalles de los criterios empleados para la generación de las series históricas se encuentran en "Series históricas sobre ocupación", material que puede solicitarse directamente
} 


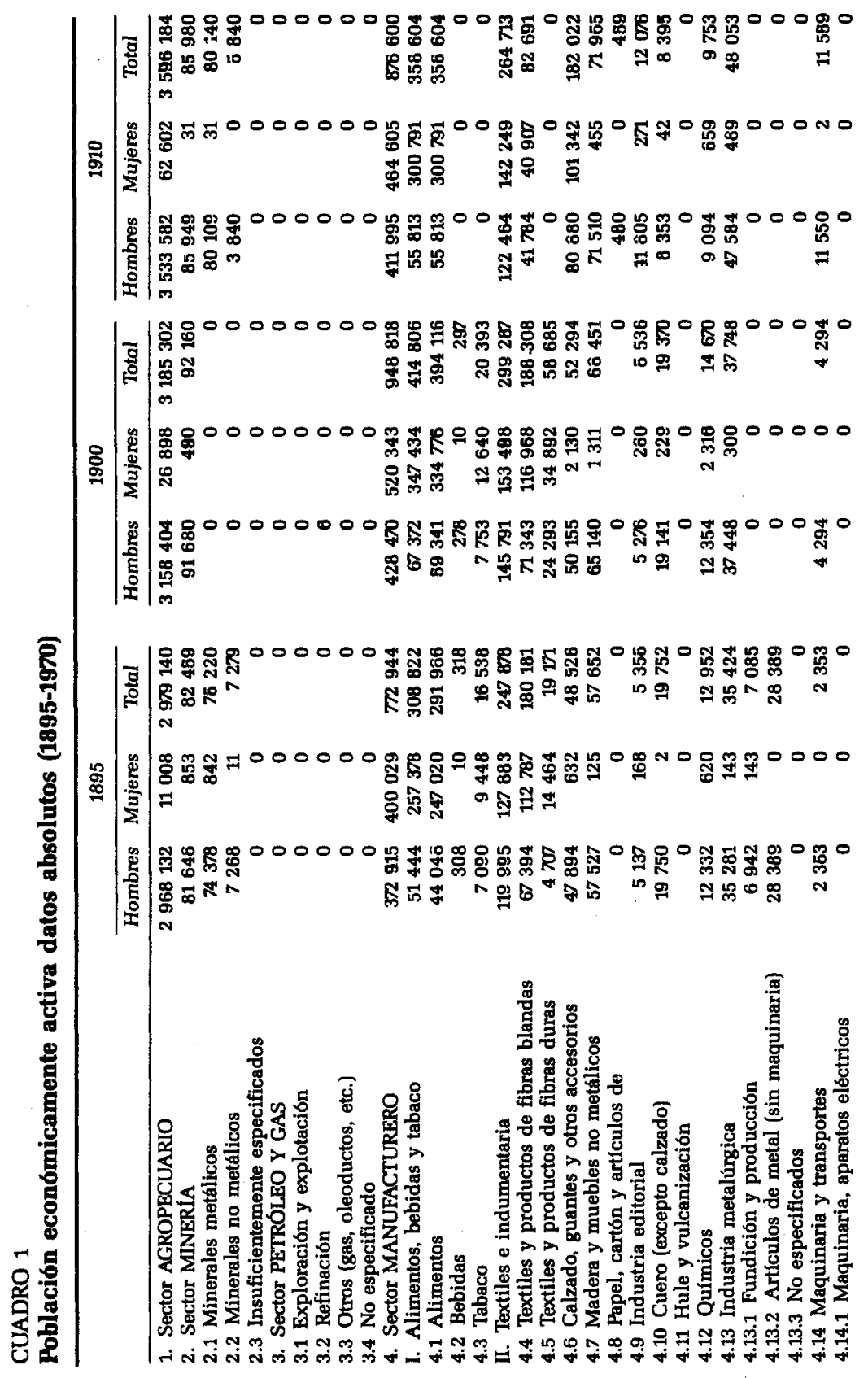




\begin{tabular}{|c|c|}
\hline 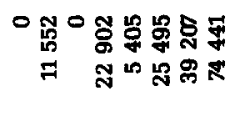 & 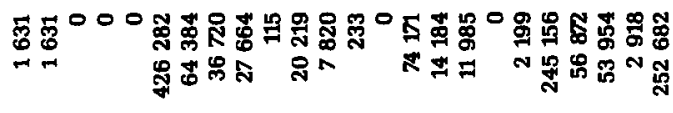 \\
\hline 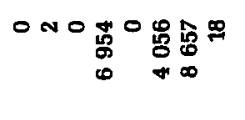 & 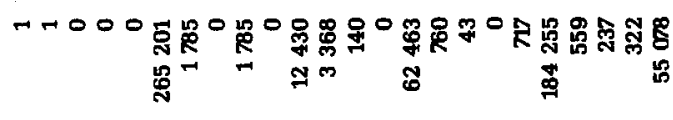 \\
\hline 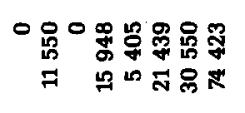 & 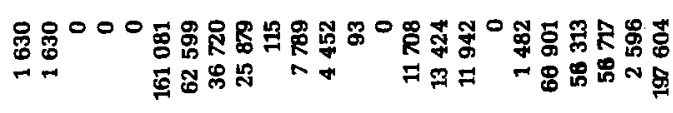 \\
\hline 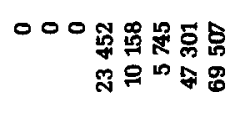 & 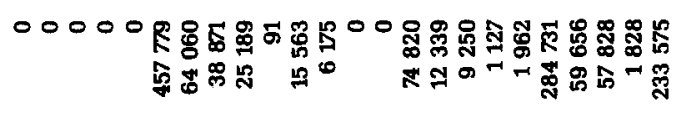 \\
\hline 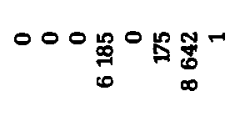 & 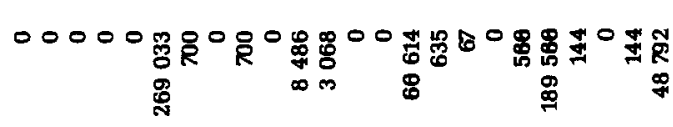 \\
\hline 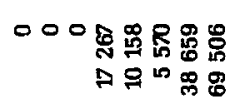 & 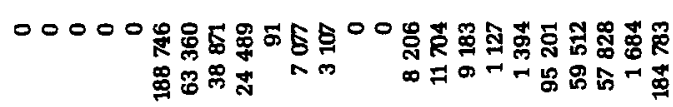 \\
\hline 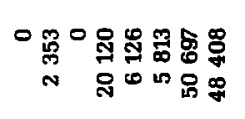 & 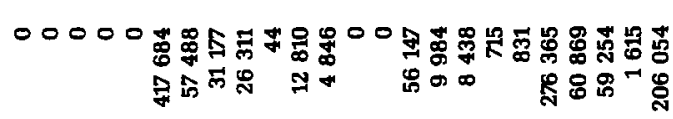 \\
\hline 앵ำ & 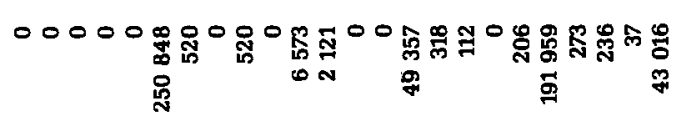 \\
\hline 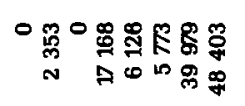 & 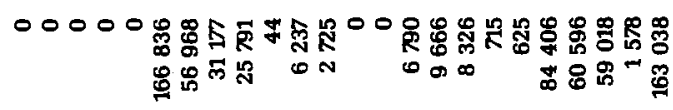 \\
\hline
\end{tabular}

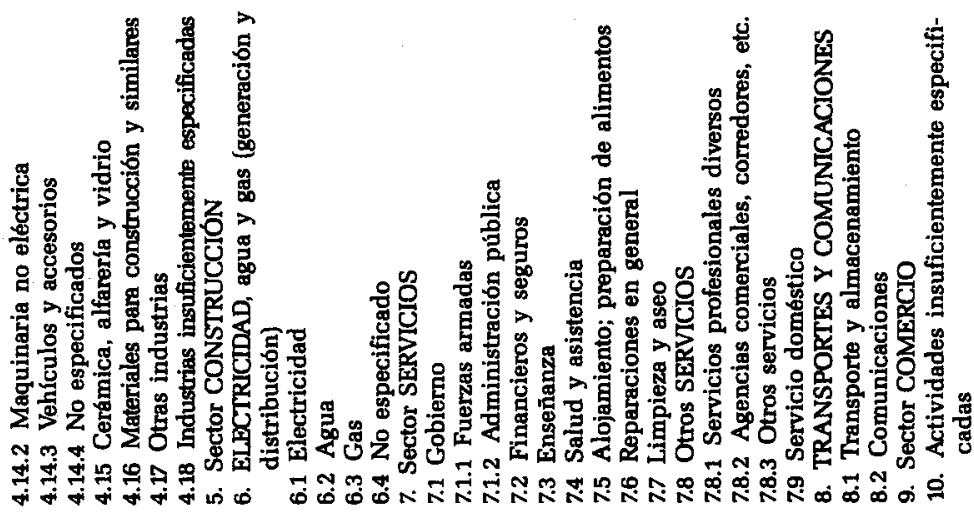




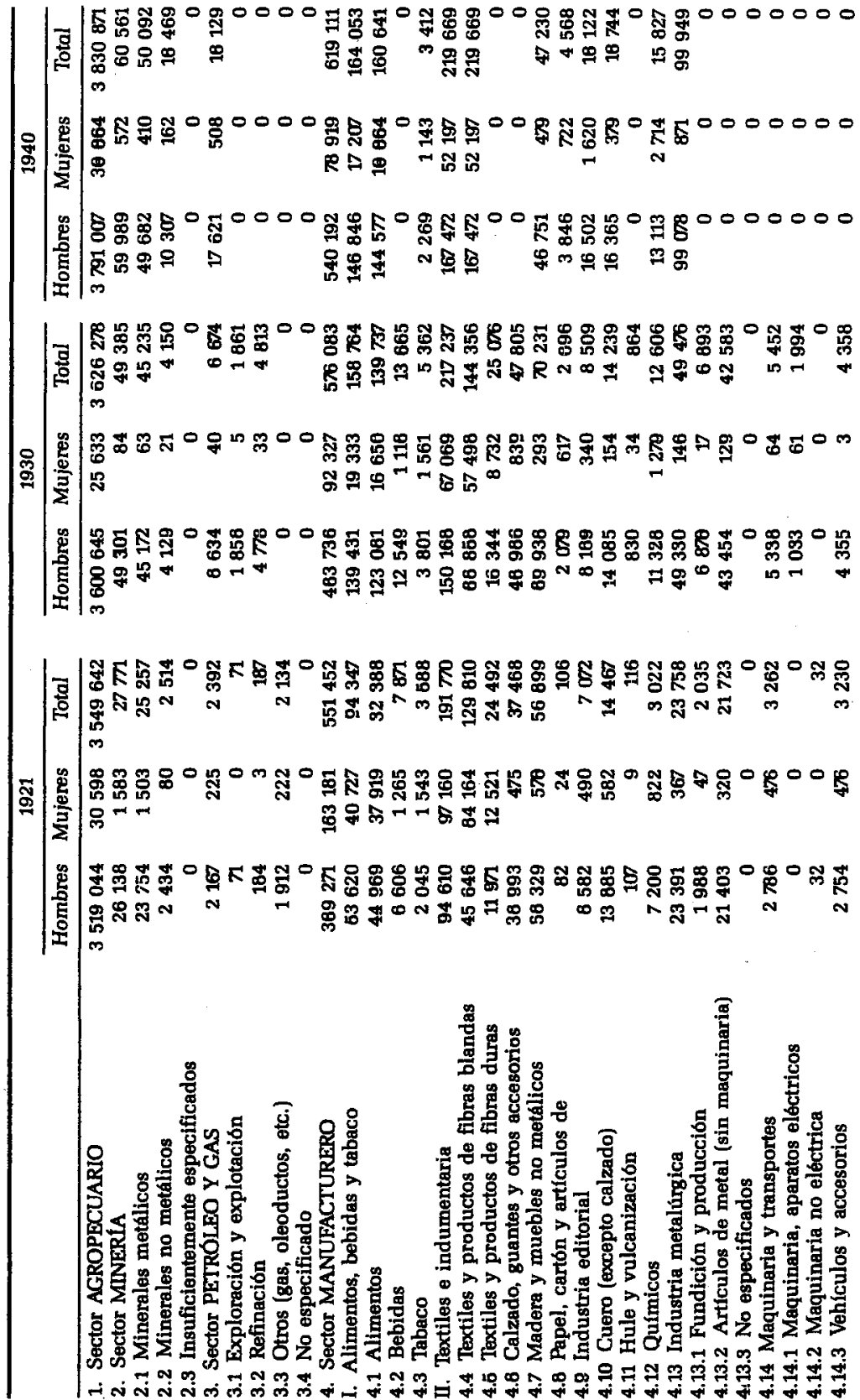




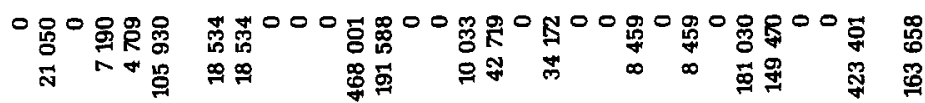

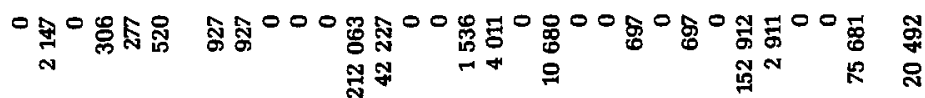

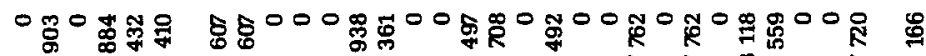
出

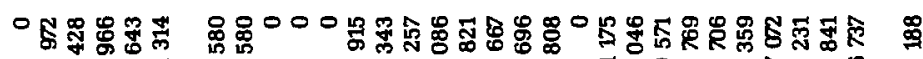

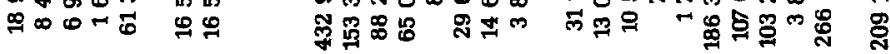

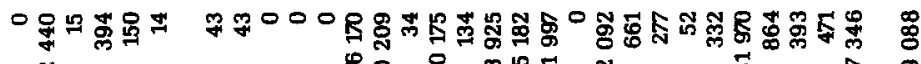

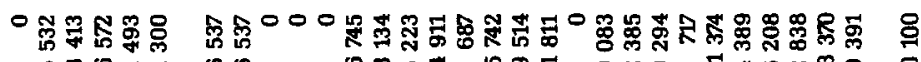

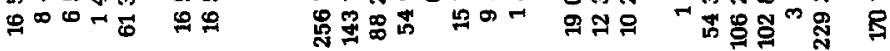

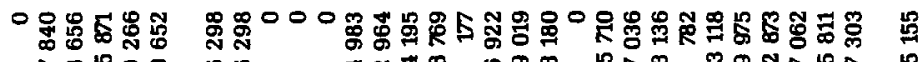

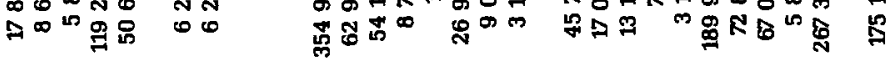

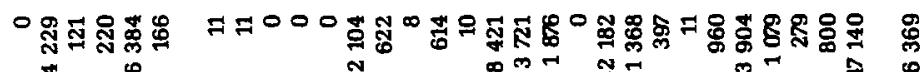
"

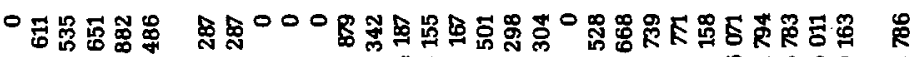

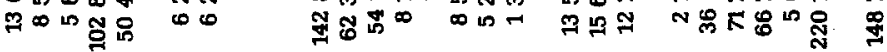

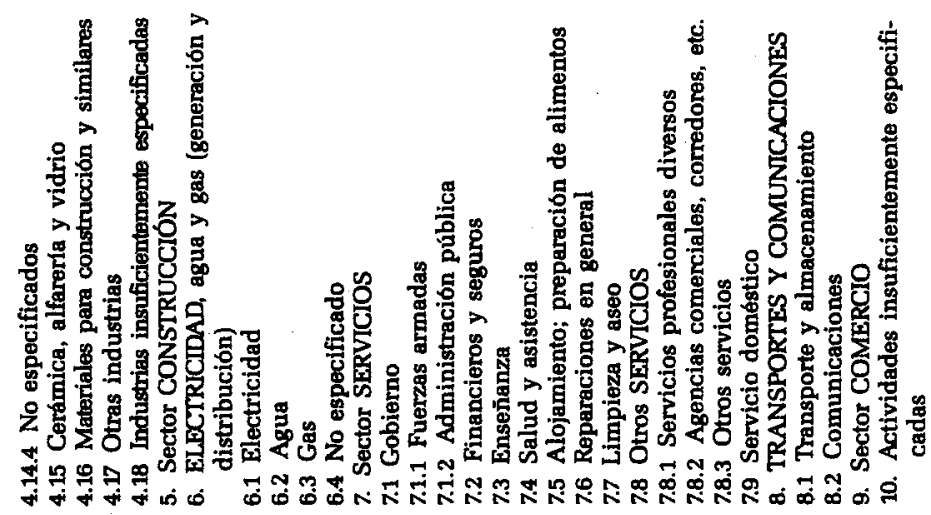




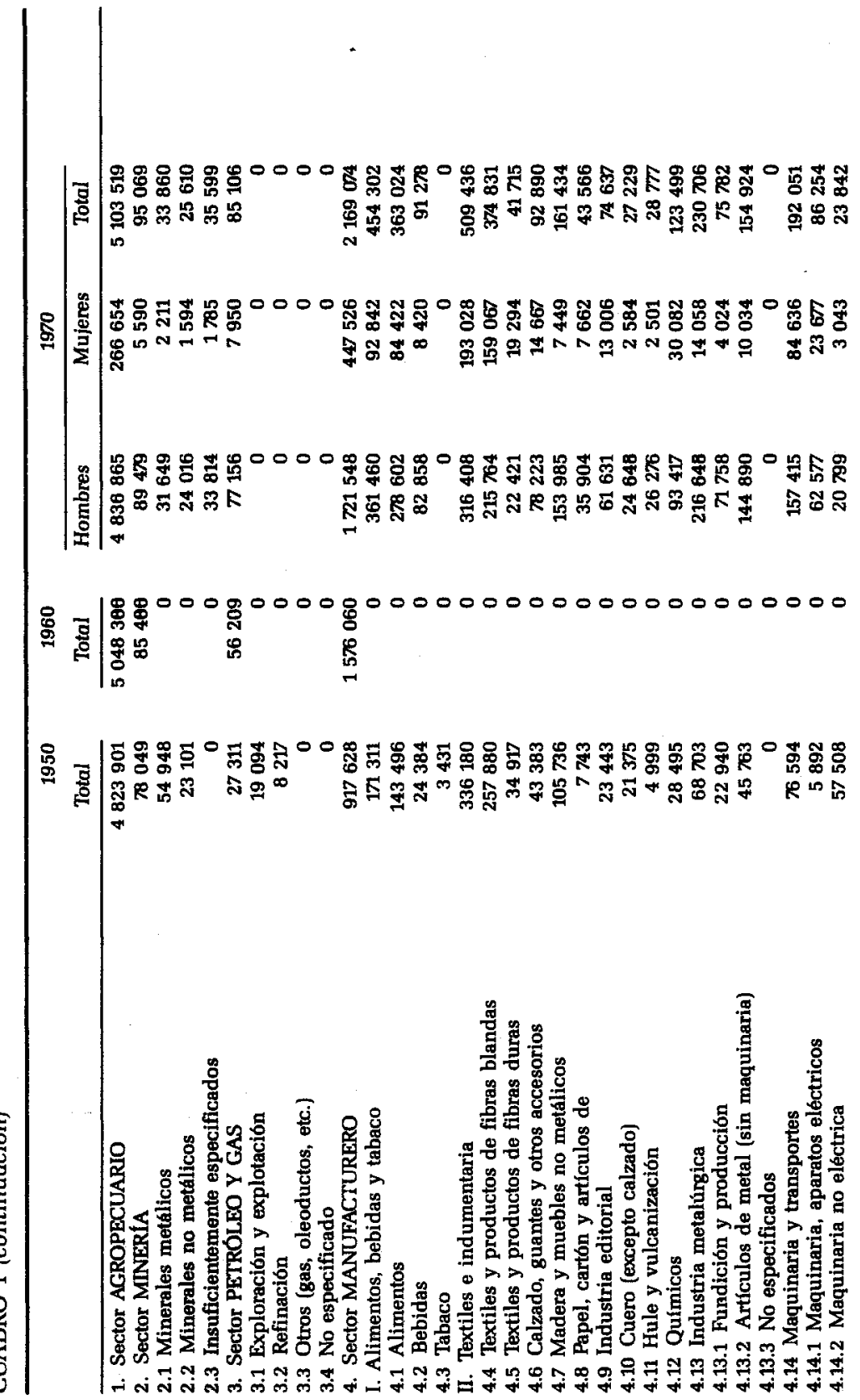




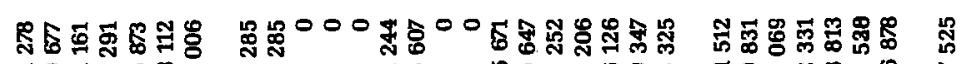

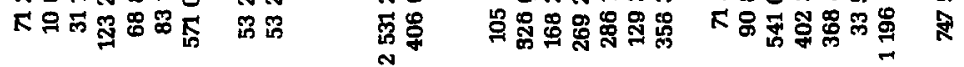

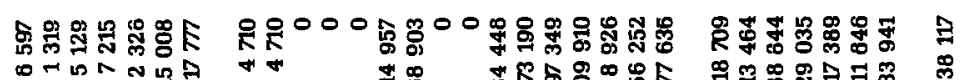

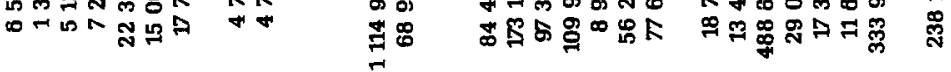

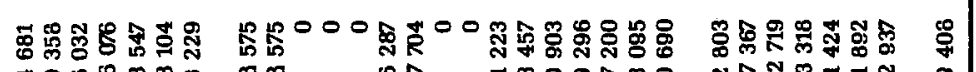

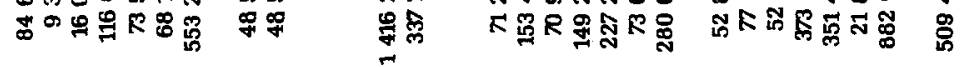

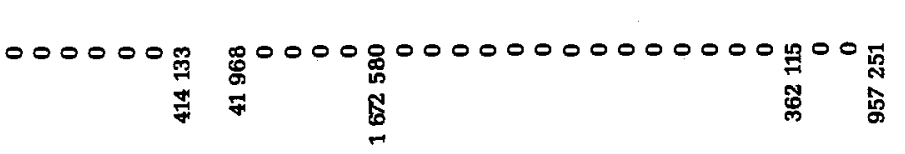

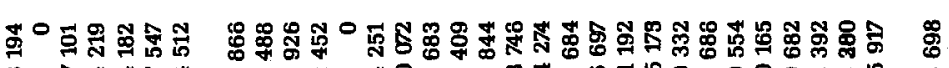

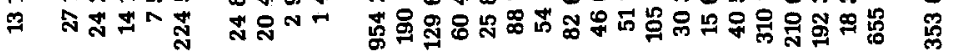


encuentran los datos de población económicamente activa (PEA), agrupada por ramas de actividad, de acuerdo con los criterios detallados en el documento citado en la nota 2. Este cuadro sirvió como punto de partida a los cuadros subsecuentes - con y sin reasignaciones de la PEA con rama insuficientemente especificada- que presentamos dentro del texto y que apoyan el análisis presente a lo largo del estudio y permiten apreciar las tendencias de largo plazo en el empleo global y sectorial.

Además de señalar estas tendencias, nos detendremos a examinar lo sucedido con la ocupación en los tres periodos que logramos identificar durante el proceso de investigación.

El primero de ellos (1895-1930) abarca el fin del auge asociado al proceso de acumulación basado en la exportación de metales y determinados productos agrícolas, así como una prolongada etapa de estancamiento económico correspondiente a la declinación de esa forma de desarrollo capitalista del país. El segundo periodo (1930-1970), cubre la fase expansiva del ciclo asociado a un patrón de acumulación que tiene como eje al sector manufacturero orientado al mercado interno; allí distinguimos dos etapas: 1930-1950, que corresponde en realidad a la transición de un patrón a otro, y 1950-1970, etapa en la que se consolidó el desarrollo industrial. Por último, nos referimos al decenio de los setenta, cuando la acumulación enfrentó serios obstáculos para continuar.

Como se constata en las gráficas adjuntas, en cada uno de estos periodos la ocupación adquiere características distintivas en cuanto a su ritmo de crecimiento y a su estructura por ramas de actividad. A lo largo del texto mostramos la existencia de algunas tendencias de largo plazo manifiestas tanto en los cambios en el volumen como en la composición del empleo; asimismo planteamos una serie de interrogantes respecto a las causas de algunas de las transformaciones en la ocupación que pueden observarse durante los diferentes periodos estudiados.

El presente trabajo es el primer resultado de un proyecto cuya finalidad es realizar un estudio exhaustivo del empleo en México a lo largo del siglo xx, para lo cual habremos de examinar no sólo los censos de población, sino también otras fuentes.

Periodo 1895-1930

Pára iniciar el análisis creímos conveniente explicitar algunos rasgos del Porfiriato que permiten comprender mejor el desarrollo de la ocupación en esa época.

En el régimen del general Díaz, México alcanzó una estabilidad inter-

a los autores. El tratamiento de la información censal de 1980 se encuentra en Rendón y Salas (1986). 
na mínima que sirvió como base a la integración real del país al mercado mundial. Destacó en esta época la exportación de productos agrícolas y metales diversos (en un principio metales preciosos y, más tarde, metales industriales como el cobre y el zinc). El nexo comercial con el exterior se acompañó de la irrupción interna de capitales extranjeros, los cuales se insertaron en las actividades más rentables y, al paso del tiempo, se convirtieron en los promotores y principales beneficiarios de un importante proceso de modernización de la estructura productiva.

Un elemento central de este proceso fue la intensa labor de construcción de vías férreas, que comunicaron los centros mineros del norte y del centro del país con los puertos del Golfo, las ciudades fronterizas de Texas e incluso con centros industriales como Chicago. Los ferrocarriles no sólo facilitaron la exportación de materias primas, sino que jugaron un papel central en la conexión de mercados regionales y en la consecuente consolidación de un mercado interno. La minería, diversos sectores de la manufactura y la producción agrícola se beneficiaron con la introduicción de nuevas tecnologías, mismas que tuvieron importantes efectos sobre los niveles de ocupación.

Si bien las exportaciones crecieron en valor a una tasa anual promedio de $6 \%$ durante el Porfiriato, la caída del precio de la plata que ocurrió en los primeros años del siglo trajo consigo un problema de balanza de pagos, a lo cual se sumó un mayor costo en las importaciones; en consecuencia, algunos empresarios mexicanos trasladaron inversiones hacia la producción doméstica. Pero, a pesar del vigoroso crecimiento de la actividad productiva, el Porfiriato mantuvo notables contradicciones económicas y sociales, manifiestas en disparidades regionales, concentración del ingreso, conflictos entre sectores empresariales, baja remuneración al trabajo agrícola y un férreo control político y social. Todas estas contradicciones habrían de manifestarse vigorosamente a partir de la crisis de 1907, que culminó con el estallido de la Revolución.

El desarrollo económico de fines del siglo xIx se reflejó en el ritmo de crecimiento registrado por la ocupación durante el último lustro. El aumento en la población que habitualmente desempeñaba una ocupación fue superior al crecimiento demográfico, de tal manera que las tasas brutas de actividad, tanto de hombres como mujeres, se incrementaron entre 1895 y 1900 (véase el cuadro 6).

A excepción de los transportes (donde la ampliación de los ferrocarriles eliminó parcialmente los medios tradicionales de traslado de productos), todos los sectores de actividad incrementaron sustancialmente su fuerza de trabajo, en especial la agricultura y la industria de transformación, que en conjunto contribuyeron con $79 \%$ de las nuevas ocupaciones que se generaron en esos cinco años. El resto del crecimiento de la ocupación se debió a otras industrias (construcción y minería), que aportaron $7 \%$, mientras que el comercio y los servicios contribuyeron con $14 \%$ (véa- 
se cuadro 3A). Las ramas de transformación de mayor dinamismo fueron la alimenticia, la de fibras duras, la de construcción de vehículos y la de materiales para construcción (cuadro 4).

En el cuadro 5 llama la atención que disminuya el peso relativo de la servidumbre en el sector servicios mientras que las actividades de aseo y limpieza lo incrementan; es muy posible que la declinación absoluta del número de mujeres empleadas en el servicio doméstico (2 500), se haya debido no a un proceso real de cambio en los servicios sino más bien a que cierta cantidad de mujeres incluidas en la servidumbre en el censo de 1895 se registró en 1900 bajo el rubro de lavanderas, ya que esta actividad crece notablemente en el periodo y es la que explica el aumento en la participación de las actividades de aseo y limpieza dentro de los servicios.

Cabe hacer notar que las fuerzas armadas registran un considerable incremento, lo que no hace sino reflejar el interés gubernamental por mantener el orden establecido.

Pero a partir de la primera década del siglo xx la capacidad de la economía para absorber nueva fuerza de trabajo empieza a verse minada; la ocupación se expande a un ritmo menor que el de la población total (véase la gráfica 1), por lo que las tasas brutas de actividad muestran una tendencia al descenso que no habria de revertirse sino hasta los años cua-

\section{GRÁFICA 1}

Tasas de crecimiento (población total y PEA)

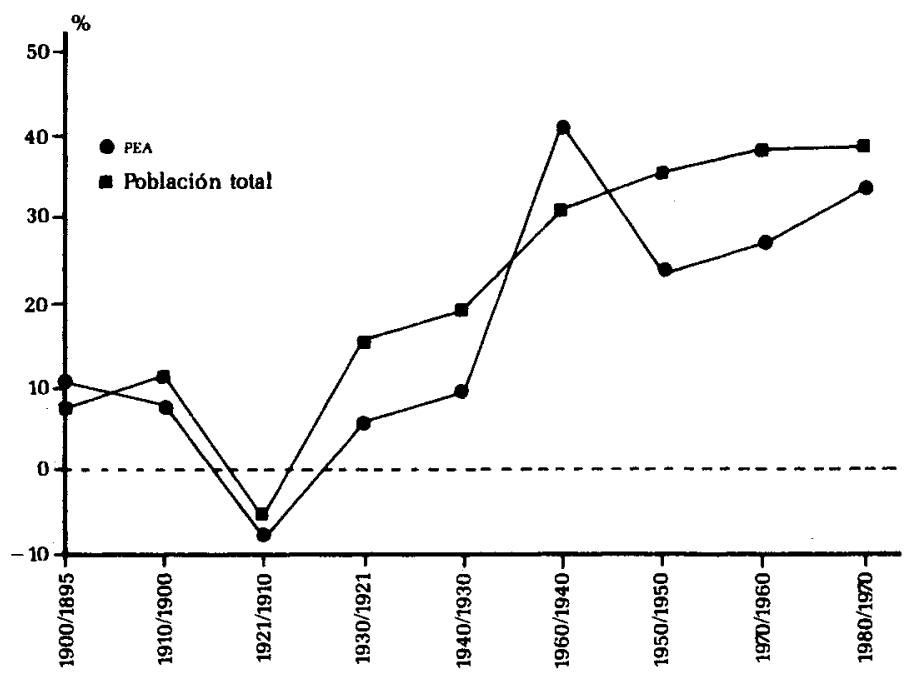


renta. Ya desde estos últimos tiempos del Porfiriato, los límites a la expansión del mercado interno, aunados a las fluctuaciones del mercado internacional, restringían, al obstaculizar el proceso de acumulación de capital, la capacidad de la economía para generar nuevas ocupaciones; esto se convirtió en un obstáculo a la expansión del mercado interno en lo que se refiere a las manufacturas y los servicios.

Durante este periodo, únicamente la ocupación agrícola conservó su ritmo de expansión; el resto de las actividades perdió dinamismo. Así, la industria extractiva mantuvo su nivel de ocupación prácticamente constante, pero la industria de transformación vio incluso reducida su fuerza de trabajo.

La crisis de 1906-1907 y la contracción del mercado interno afectaron la mayor parte de las ramas de la industria de transformación, salvo la metalúrgica, la de fabricación de vehículos y aquéllas ligadas al consumo de las minorías privilegiadas. Fue notable la caída en la ocupación (en especial de mujeres) en las industrias textil y del vestido, donde el efecto de la crisis de realización se sumó a la modernización de estas ramas.

En el sector servicios, el incremento en actividades como la enseñanza, los servicios profesionales y la administración pública se vio más que contrarrestado por el descenso que registraron los servicios de aseo y limpieza, las fuerzas armadas y sobre todo la servidumbre. ${ }^{3}$ Así, en 1910 el peso relativo de la industria de transformación y de los servicios en la ocupación global fue inferior al de 1895 y al de 1900 (véase el cuadro 2).

Los efectos de la Revolución y de la inestabilidad política de los años siguientes explican las caidas observables en casi todas las ramas, según los datos del censo de 1921. A los hechos citados, se suman las tendencias al estancamiento-recesión en casi todos los sectores económicos; la ocupación se redujo en tal magnitud que, en 1921, su mónto global era ligeramente inferior al registrado en 1900. Los únicos sectores que en esta segunda década aumentaron su contingente de fuerza de trabajo fueron el comercio $y_{1}$ sobre todo, los transportes y las comunicaciones.

La contracción de la fuerza de trabajo ligada a ciertas actividades se explica en gran medida por la liberación de la mano de obra en las haciendas, no sólo de peones agrícolas, sino también de servidumbre; incluso la drástica caída en la población femenina ocupada en la industria de transformación fue parte de esa liberación. Entre 1895 y 1910, la inmensa mayoría de las mujeres ocupadas en la industria alimenticia estaba integrada por molenderas, quienes se dedicaban a la molienda de maíz y chile para la comida de los peones de las haciendas; en el censo de 1921 esa

\footnotetext{
${ }^{3}$ No se ha explicado la caida sistemática de la servidumbre entre 1900 y 1921. Es posible que el movimiento armado de 1910, al liberar enormes contingentes de fuerza de trabajo ligados a las haciendas, haya producido el abatimiento en la servidumbre. No obstante, esta explicación no se aplica al periodo 1900-1910. Tampoco parece razonable atribuir la declinación a problemas ligados con el censo de 1910.
} 


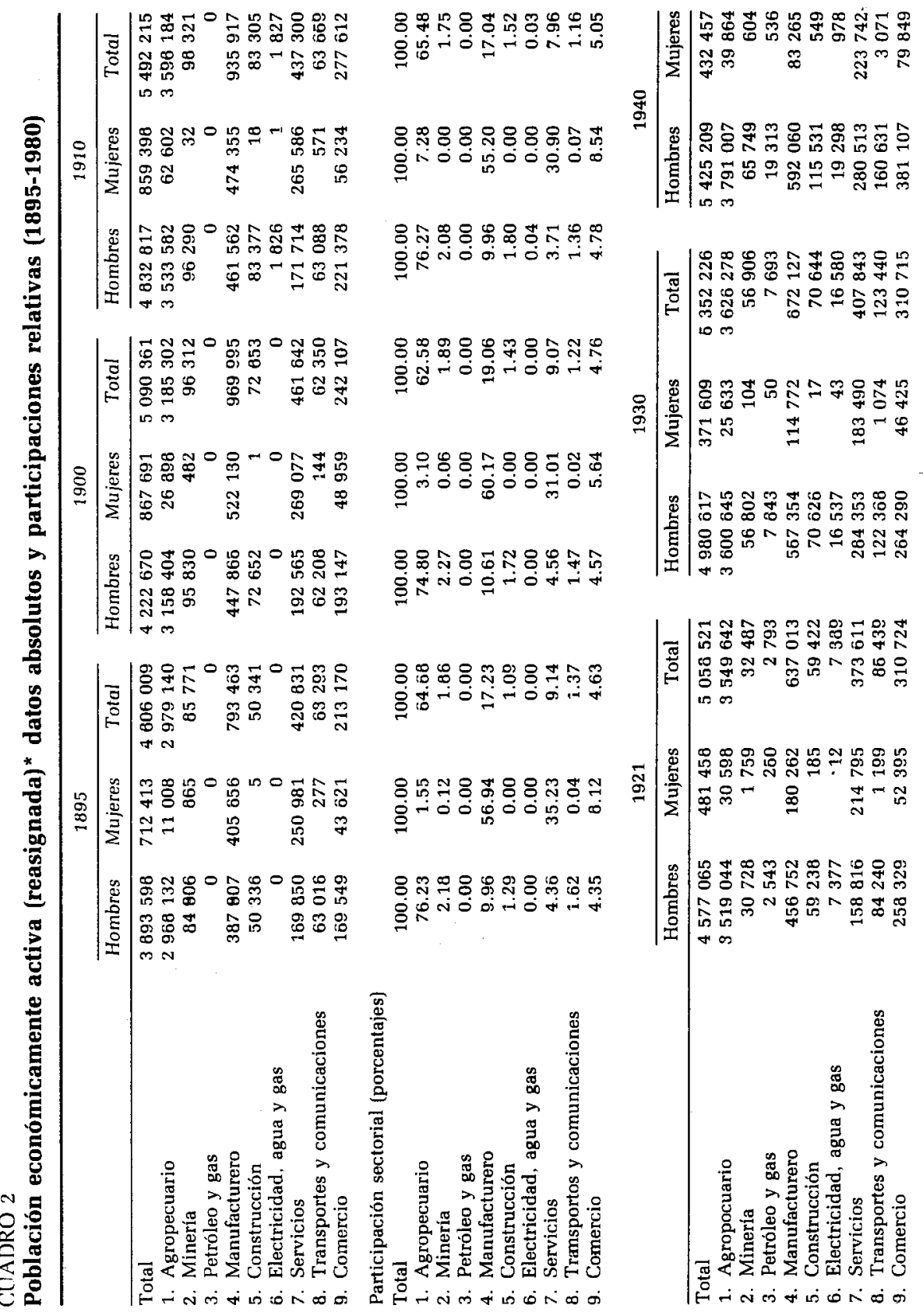




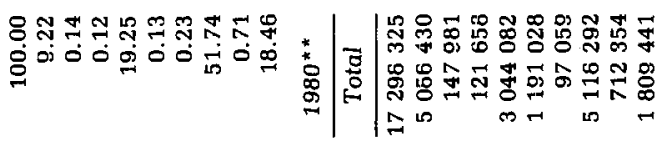

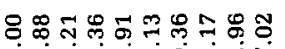

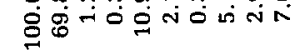

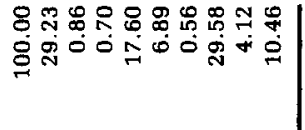

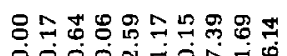

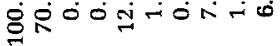

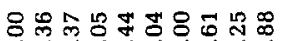

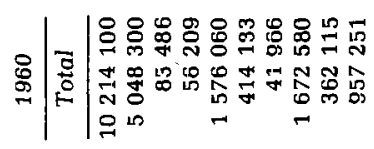

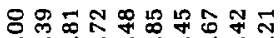

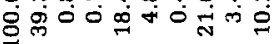

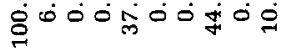

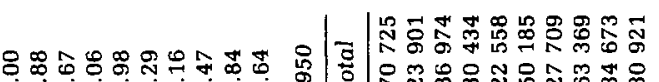

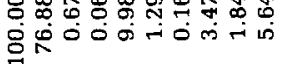

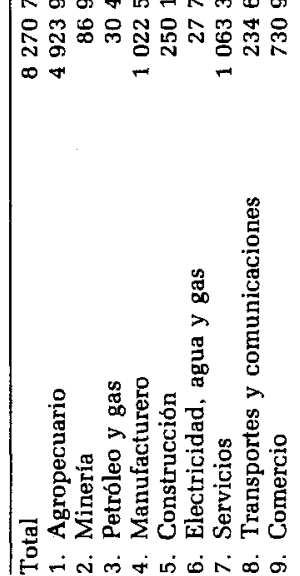

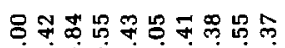

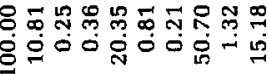

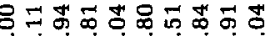

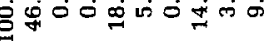

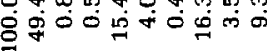

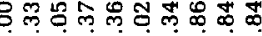

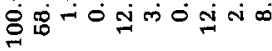

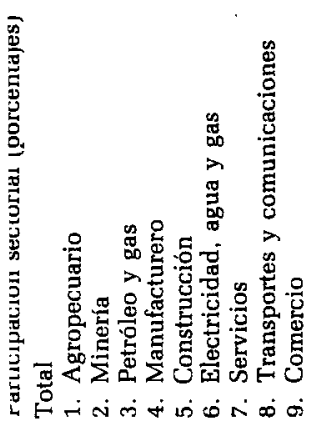


ocupación había desaparecido, ${ }^{4}$ con lo cual termina el predominio de las mujeres en la fuerza de trabajo de la industria alimenticia y del conjunto de la industria de transformación (véase el cuadro 4). Asimismo, la caída en el monto de mujeres en los servicios de aseo y limpieza en 1921 (véase el cuadro 5) se debe a que el monto de lavanderas (asociadas en su mayoría al sistema de las haciendas) se redujo a la mitad durante esos 10 años.

La situación política de la época se refleja en la composición de la población ocupada en el sector gubernamental: mientras en 1910 las fuerzas armadas representaban $57 \%$, en 1921 su participación se elevó a 86\% (a la vez que el número de empleados en la administración pública se redujo a menos de la cuarta parte), para disminuir a $62 \%$ en 1930 .

Además de los efectos directos e indirectos de la Revolución en el monto y estructura de la ocupación, ciertos cambios revelan la continuidad del incipiente proceso de modernización de la economía. Como era ya perceptible desde principios de siglo, la estructura ocupacional de los servicios y de la industria de transformación empieza a diversificarse (véanse los cuadros 4 y 5); de hecho, en el censo de 1921 se registraron nuevas actividades, como la fabricación de productos de hule y de maquinaria, y los servicios de alojamiento y preparación de alimentos (aunque el monto de trabajadores que ocupaban era todavía insignificante), también se redujo la fuerza de trabajo ocupada en las industrias tradicionales (minería; fabricación de alimentos, bebidas y tabaco; textiles y de confección de ropa) y el contingente de obreros en establecimientos industriales se incrementó notablemente. ${ }^{5}$ Estos dos últimos procesos parecerían indicar un ascenso de la producción fabril y del trabajo asalariado en la industria, en detrimento de la producción artesanal realizada en forma casi siempre independiente.

En la década de los veinte, la ocupación global se incrementó en menos de $6 \%$, pero este fue el resultado neto de un aumento de la fuerza de trabajo masculina de más de $\mathbf{4 0 3}$ mil personas y de una reducción en el número de mujeres ocupadas en cerca de 110 mil. Como consecuencia de los cambios producidos por la Revolución en las estructuras sociales, y de la creciente modernización de la industria, la participación de las mujeres en la fuerza de trabajo continuó contrayéndose. Entre 1900 y 1930 se acentuó la división del trabajo por sexos (producción doméstica a cargo de las mujeres y producción para el mercado a cargo de los hombres).

Los sectores que contribuyeron en mayor proporción al incremento en

\footnotetext{
${ }^{4}$ Es posible que esta ocupación no haya desaparecido del todo y que su ausencia en el censo de 1921 refleje un cambio en el criterio de captación, siendo incluidas las molenderas en el rubro de trabajos domésticos.

${ }^{5}$ En el cuadro 3, en los años 1895, 1900, 1910 y 1921, los obreros industriales están incluidos (junto con los empleados) en el rubro de otras industrias no especificadas, ya que se desconoce en qué rama de actividad se encontraban ocupados. En 1921, 91\% de las personas registradas en industrias insuficientemente especificadas correspondian a obreros en establecimientos industriales.
} 
el empleo masculino fueron, en orden de importancia, los servicios, las manufacturas y la agricultura, mientras que la reducción en el empleo de mujeres tuvo lugar sobre todo en los dos primeros sectores (que explican la caída de 28 y $60 \%$, respectivamente; véase el cuadro $3 \mathrm{~A}$ ).

Al interior de la industria de transformación no es posible distinguir cuáles de las ramas contribuyeron en mayor medida a la creación de nuevas ocupaciones masculinas, debido a dificultades de comparación intercensal, ${ }^{6}$ pero es posible advertir cómo la reducción de la mano de obra femenina en este sector se dio principalmente (de igual manera que en los dos decenios anteriores) en las industrias alimenticias, textil y de confección de ropa.

En el sector servicios se observa, nuevamente, la reducción en el número de mujeres ocupadas en el trabajo doméstico para otros y en las actividades de aseo y limpieza. Si bien la participación de mujeres continuó siendo alta en el conjunto de las actividades de servicios, a partir de 1930 la fuerza de trabajo masculina se volvió predominante.

La expansión de las actividades gubernamentales que tuvo lugar entre 1921 y 1930 se reflejó en la creación directa de empleos; de los $114 \mathrm{mil}$ hombres que se incorporaron al sector servicios, $71 \%$ correspondió a la administración pública y a las fuerzas armadas.

Cabe advertir que los datos del censo de 1930 muestran un incremento en la población masculina ocupada en el servicio doméstico. Tal aumento parece reflejar, más que un hecho real, un error de clasificación, pues lo más probable es que se haya clasificado como trabajadores domésticos a los individuos que se identificaba en censos anteriores como empleados particulares.

Si bien en los años veinte se produjeron importantes cambios sociales, políticos e institucionales que habrían de permitir un posterior desarrollo industrial, los cambios en la estructura productiva fueron modestos. En 1930, México seguía siendo un país predominantemente agrícola; más de las dos terceras partes de la población ocupada se concentraba en actividades primarias y una buena parte de la producción de bienes y servicios se realizaba en el seno de los hogares.

Periodo 1930-1970

Etapa de transición: 1930-1950

Entre 1930 y 1940 la economía registró marcadas fluctuaciones, incluida la gran recesión de los primeros años de esa década. En el segundo lustro

\footnotetext{
${ }^{6}$ En el censo de 1930 se clasificó a la población trabajadora en ramas de actividad, lo que implica que los obreros de establecimientos industriales están incluidos en la rama correspondiente, asignación que no fue posible realizar con los datos de los censos anteriores.
} 


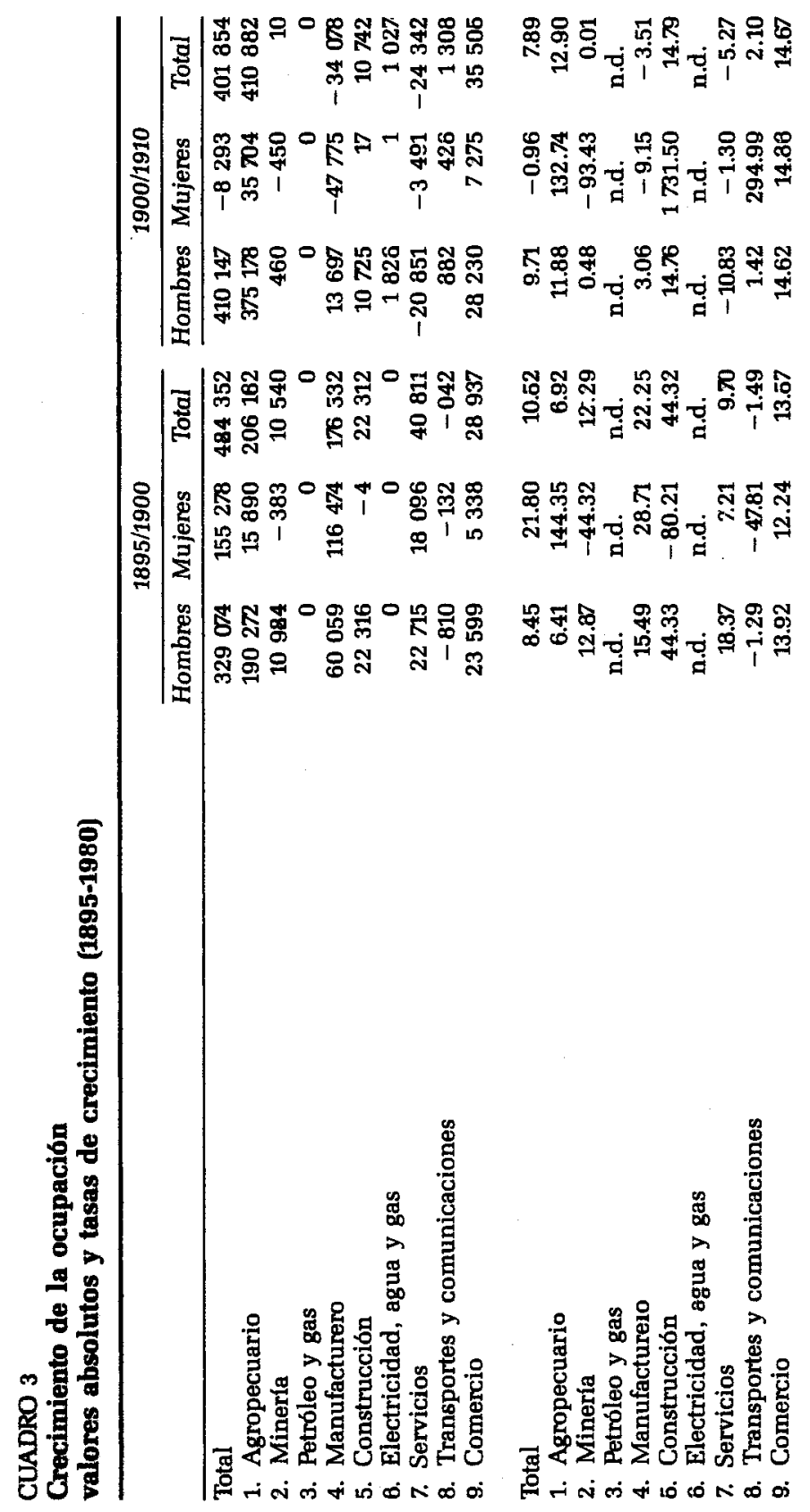



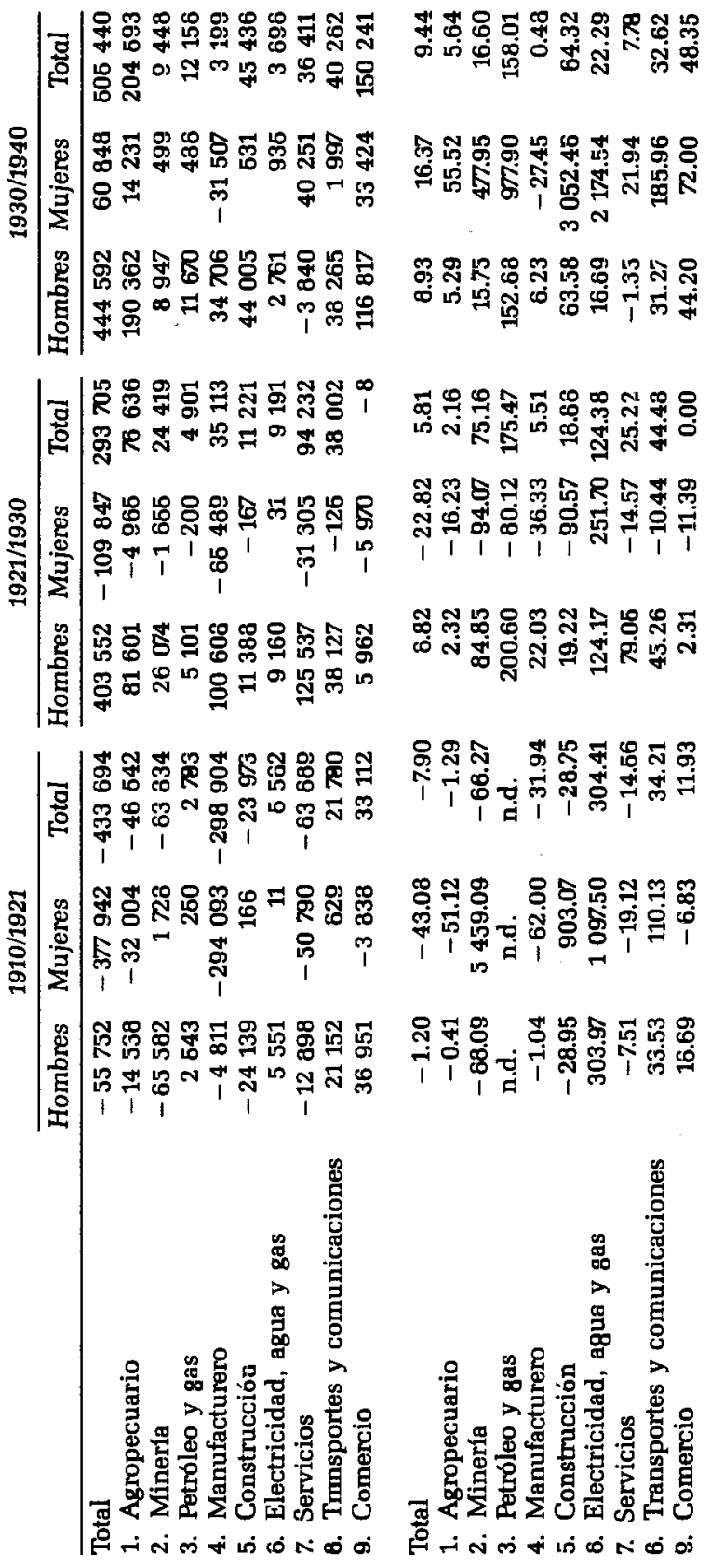


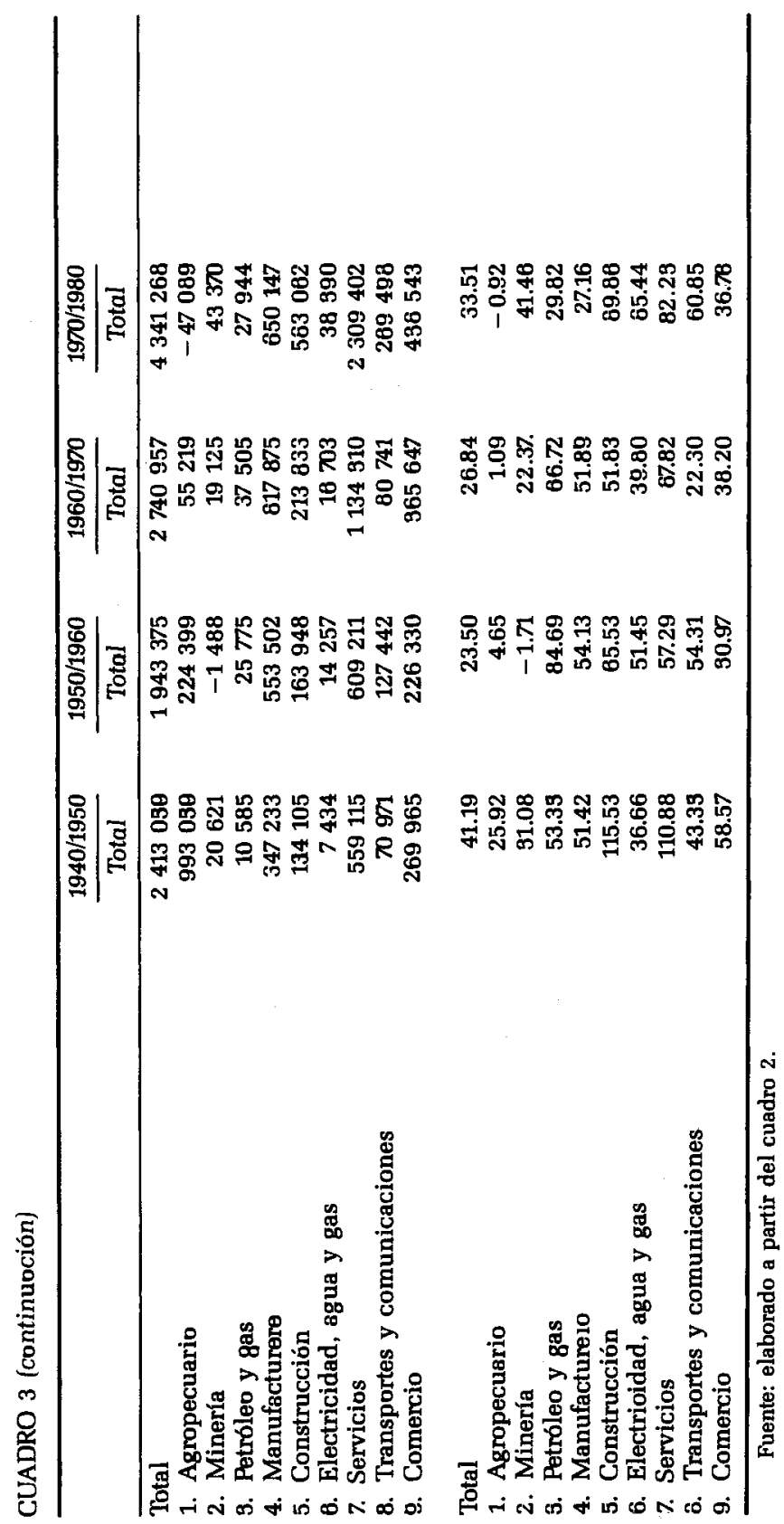


del periodo, el Estado se había consolidado por fin y la administración cardenista llevó a cabo importantes reformas, las cuales habrían de permitir la ampliación del mercado interno. En ese lapso, la ocupación global aceleró su ritmo de crecimiento con relación al periodo intercensal precedente. Esto se debió no sólo a que los servicios y, en general, las actividades terciarias continuaron ampliándose, sino también a un incremento significativo en la ocupación agrícola, atribuible principalmente al reparto agrario realizado por Cárdenas. Por su parte el conjunto de las industrias contribuyó sólo con $15 \%$ de las nuevas ocupaciones ${ }^{7}$ (véase el cuadro 7); la industria extractiva, la generación y distribución de electricidad y la construcción incrementaron su fuerza de trabajo a tasas relativamente altas, pero en la industria de transformación el crecimiento fue insignificante y la fuerza de trabajo femenina continuó disminuyendo (véase el cuadro 3 ).

Esto parece atribuible, más que a un bajo ritmo de actividad, a una expansión acelerada de la industria fabril a costa de la producción artesanal; ${ }^{8}$ un hecho que ayudaría a confirmar esto es que al advenimiento de la Segunda Guerra Mundial la industria mexicana fue capaz de incrementar su producción con aumentos en la inversión muy bajos, lo cual habla de un cierto monto de capacidad instalada ociosa.

Otra característica distintiva del comportamiento de la ocupación en los años treinta fue que el empleo de mujeres comenzó a aumentar, pues su creciente participación en las actividades terciarias compensó con creces la caída que todavía en esa década registró la fuerza de trabajo femenina en las industrias tradicionales; no obstante, continuó el descenso de la tasa bruta de actividad femenina, alcanzando en ese año el límite más bajo del largo periodo 1895-1980 (véase el cuadro 6).

En los años cuarenta, la ocupación registró el ritmo de crecimiento más alto del siglo y, excepcionalmente, superó al incremento demográfico (véase la gráfica 1), pese a que éste se había acelerado de manera significativa a consecuencia de la disminución en la tasa de mortalidad (Alba, 1984: 44-46). Este auge de la ocupación se explica por la coincidencia de un crecimiento acelerado de la producción manufacturera y de la acumu-

\footnotetext{
${ }^{7}$ La deficiente clasificación de la PE^ por clases de actividad del censo de 1940 impide establecer comparaciones - a nivel desagregado - para la mayor parte de lás actividades secundarias y terciarias. Por ejemplo, parte de las ocupaciones de la industria metalúrgica están incluidas en las industrias extractivas; la fabricación de materiales para construcción están contenidas en la industria de la construcción, cuando dichas actividades forman parte de la industria de transformación. Asimismo, algunos servicios están incorporados en comercio. Además, el desglose de actividades de transformación y de servicios es mucho menor que el correspondiente a los censos de 1930 y 1950.

${ }^{8}$ Según datos de los censos industriales de 1930 y 1935 , en ese periodo el personal ocupado en los establecimientos censados pasó de 313153 a 318 041, a pesar del cambio de criterio en la captación. En 1935 sólo se censaron aquellos establecimientos con un valor bruto de la producción mayor a los 10 mil pesos anuales.
} 


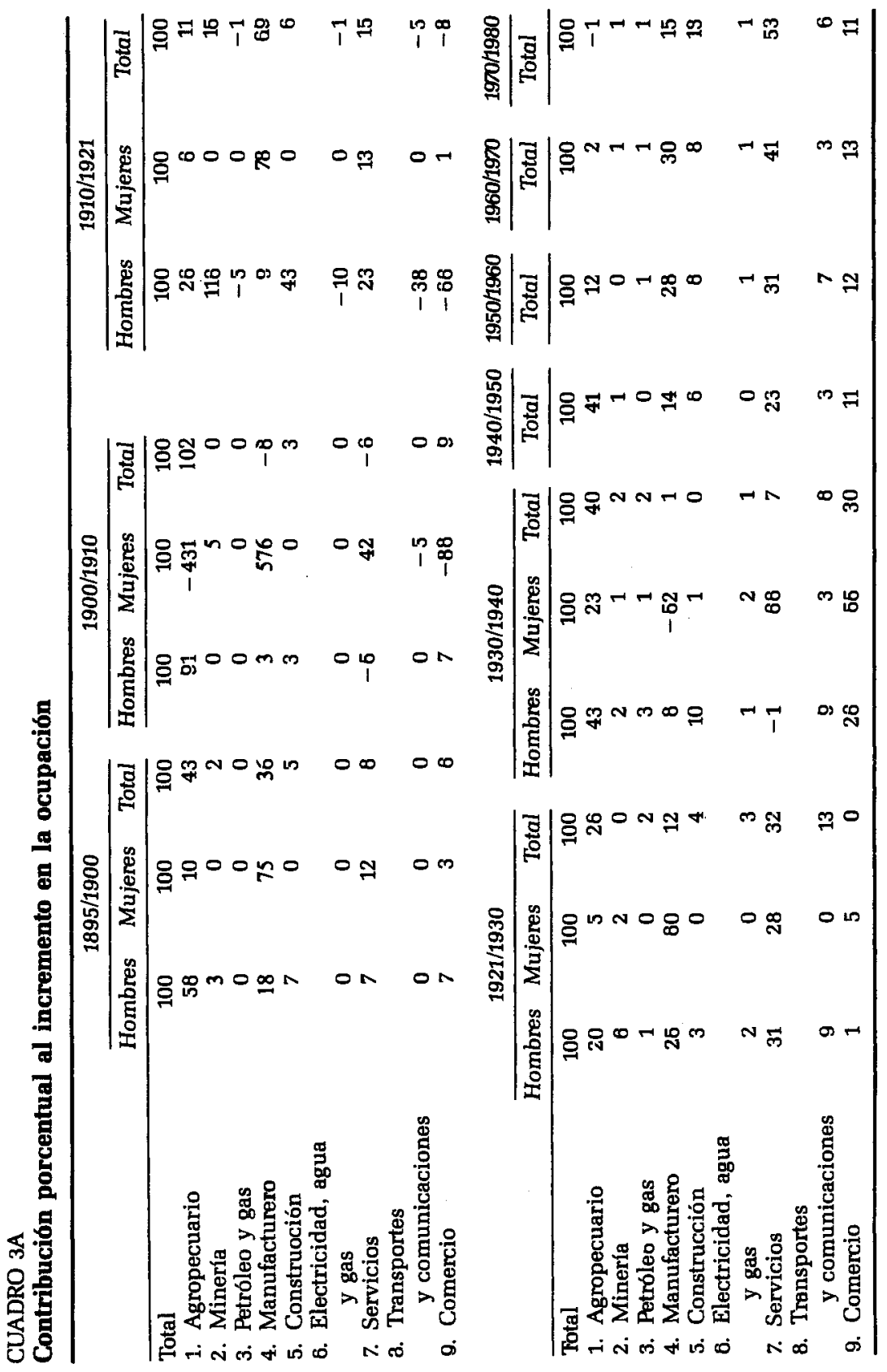


GRÁFICA 2

Ocupación agropecuaria y no agropecuaria (tasas de crecimiento)

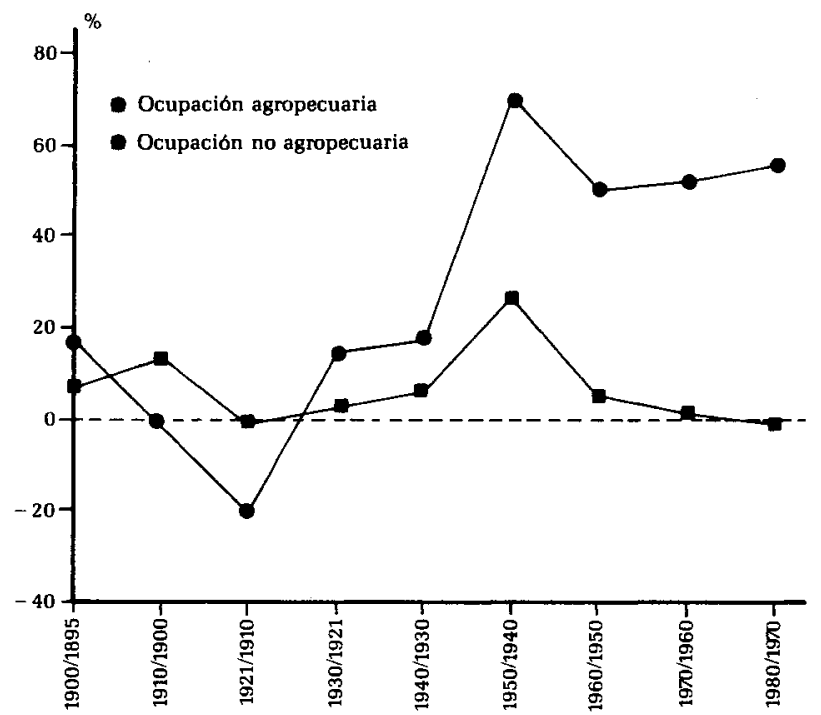

lación en ese sector -aparejado de un aumento inusitado de la ocupación en el comercio, los servicios y la construcción- con una expansión extraordinaria del empleo en la agricultura, atribuible principalmente a la ampliación de la frontera agrícola. En esta etapa se construyeron grandes obras de irrigación, que dieron origen a un incremento sin parangón de la superficie cultivable (Reyes Osorio, 1974: 111-130). La gráfica 2 ilustra claramente esta situación: en los años cuarenta tanto la ocupación agrícola como la no agrícola registraron el mayor crecimiento del siglo.

No obstante el considerable incremento del empleo en la agricultura, el peso relativo de este sector en la ocupación global muestra ya una clara tendencia decreciente (véase el cuadro 2). A diferencia de lo que ocurrió durante los años treinta, entre 1940 y 1950 el empleo en las manufacturas se incrementó notablemente. En 1950, el número de trabajadores ocupados en la industria de transformación era semejante al que existía en 1900, pero la estructura de la ocupación se había modificado radicalmente. A principios de siglo predominaban las actividades de elaboración de alimentos (allí la mayor parte de la fuerza de trabajo masculina estaba integrada por panaderos y matanceros, y entre la fuerza de trabajo femenina destacaba el número de molenderas y tortilleras), la fabricación de textiles, ropa y calzado con técnicas rudimentarias (predominaban los tejedores, 
las costureras, los sastres y los zapateros). Estas actividades absorbían $73 \%$ de la población ocupada en la industria de transformación. En 1950, en cambio, las personas dedicadas a la fabricación de alimentos, textiles e indumentaria representaban $52 \%$ de la población total ocupada en el conjunto de las manufacturas (véase el cuadro 4).

Precisamente en esta etapa de ampliación significativa del mercado interno surgió el grueso del aparato comercial del país. Esto explica que la ocupación en el comercio haya crecido, sobre todo en los años cuarenta, a un ritmo sin precedente e incluso superior al que habría de registrar en la etapa siguiente, cuando se intensificó el proceso de industrialización. Anteriormente, una parte sustancial de las necesidades de alimentación y vestido (a las que se circunscribía el consumo de las mayorías) se satisfacían con productos de fabricación casera y parte importante de la producción mercantil era de carácter artesanal (productor y comerciante eran por lo general una misma persona); por lo tanto, el aparato distributivo era modesto. No fue sino en el momento en que el capital se apoderó del grueso de la producción que la actividad comercial se convirtió en una fuente de trabajo con verdaderas posibilidades de crecer.

El extraordinario crecimiento de la ocupación en el sector servicios en este subperiodo (que tuvo lugar sobre todo en los años cuarenta), se vio acompanado de una diversificación también notable que denota no sólo la modernización de la economía sino la de la sociedad. Entre las actividades que vieron crecer en mayor medida su ocupación están los servicios financieros, los de alojamiento y preparación de alimentos, los de reparación, los de diversión, las agencias comerciales y los servicios de profesionales. En los servicios comunales el empleo también creció a tasas relativamente altas, aunque menos espectaculares.

\section{Etapa de consolidación: 1950-1970}

Al inicio de este periodo, las actividades industriales (manufactureras, minería, electricidad, petróleo y construcción) ocupaban $17 \%$ de la fuerza de trabajo, participación que aumento a $21 \%$ en 1960 y a $25 \%$ en 1970 (véase el cuadro 2). La magnitud que a principios de los años cincuenta habían adquirido el mercado interno y la planta industrial, así como la penetración creciente de capital extranjero, habrían de permitir que el proceso de industrialización se ampliara y se expandiera a la fabricación de bienes de consumo duradero y de producción, de tal manera que ya en esa década el sector manufacturero se había consolidado claramente como el eje de la acumulación. En el cuadro 4 puede constatarse una expansión generalizada del empleo en las manufacturas entre 1950 y 1970 , pero destacan por su mayor dinamismo la elaboración de bebidas, las industrias del papel y editorial, las del hule y vulcanización, la química, la metalúrgica, 
las de vehículos y accesorios (que se desarrollaron fundamentalmente en los años sesenta), y la fabricación de materiales para la construcción. Así, en esos veinte años el incremento de la población ocupada en las manufacturas fue de tal magnitud, que la importancia relativa de este sector en la fuerza de trabajo existente en el país aumentó de 12 a $18 \%$.

A la par de una mayor presencia de capital extranjero en el país, el aparato industrial se orientó en forma creciente a la producción de bienes de consumo duradero (en su mayoría intensivos en capital), y las industrias tradicionales intensificaron su modernización (elevando su densidad de capital). Ambos procesos trajeron consigo una disminución relativa de la demanda de obreros; sin embargo, debido al crecimiento rápido y sostenido de la producción y de la planta productiva, que se registró en los años sesenta (sobre todo a partir de 1963), el monto de las nuevas ocupaciones generadas en la industria fue superior al que se logró en la década anterior (véase el cuadro 3 ). ${ }^{9}$

En estos veinte años se observa una expansión generalizada de la ocupación en las actividades secundarias y terciarias (por ejemplo en el sector servicios pasó de poco más de un millón de personas a 2.8 millones y el comercio incrementó su fuerza de trabajo en cerca de 600 mil personas); sin embargo, en la mayor parte de estas actividades el ritmo de crecimiento ya no fue tan alto como en los años cuarenta.

La causa principal de que en ese lapso la economía redujera su capacidad de generar nuevas ocupaciones fue el comportamiento del empleo agrícola. En los años cincuenta, el número de trabajadores ocupados en ese sector creció lentamente y en el decenio siguiente alcanzó prácticamente su límite máximo. Tal comportamiento no fue sino una consecuencia lógica de la evolución de la estructura agraria y del papel que ha desempeñado la agricultura en el desarrollo del capitalismo mexicano a lo largo de los cuatro decenios que abarca este periodo.

Después de la Revolución y sobre todo a partir del momento en que el Estado se consolida, empiezan a configurarse dos tipos de agricultura: un sector minoritario de agricultores capitalistas que concentra las mejores tierras (incluso el grueso de la superficie de riego existente) y la mayor parte de los medios de producción agrícolas, que cuenta con un abastecimiento permanente de mano de obra abundante y barata, y produce tanto para el mercado interno como para la exportación. El otro sector está integrado por un gran número de campesinos (pequeños productores directos) con tierras por lo general de mala calidad y con escasos medios de producción, que produce sobre todo bienes alimenticios básicos destinados en parte al mercado y en parte al autoabastecimiento (Bartra, 1976).

${ }^{9}$ Debido a que en el censo de 1960 no se incluyen datos desagregados por ramas de la población ocupada en la industria manufacturera, no es posible analizar el cambio de la estructura del empleo industrial sino entre 1950 y 1970. 


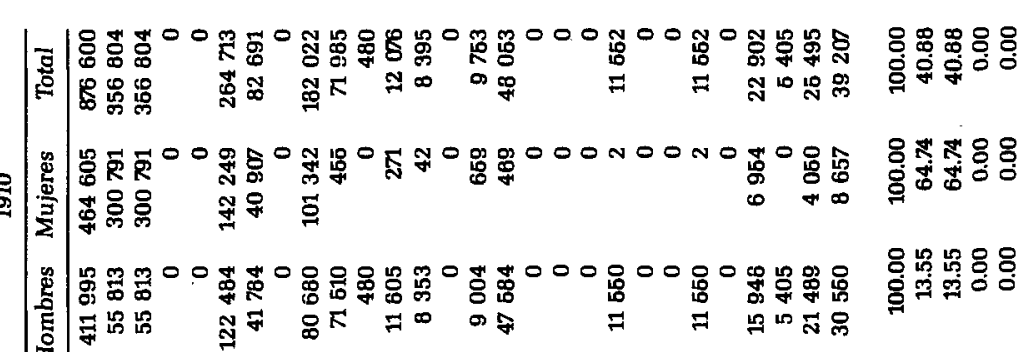

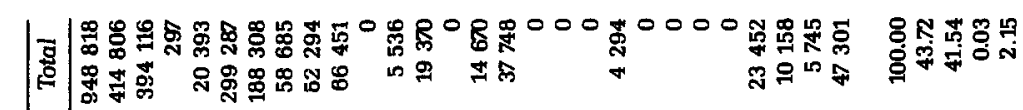

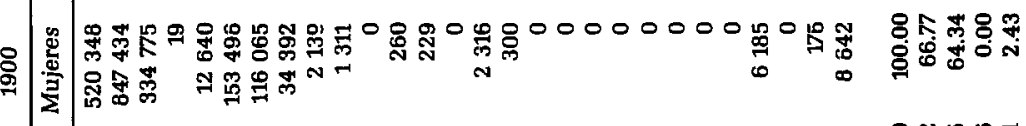

尊

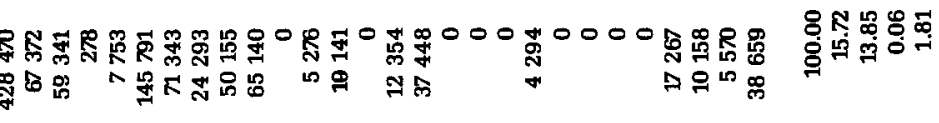

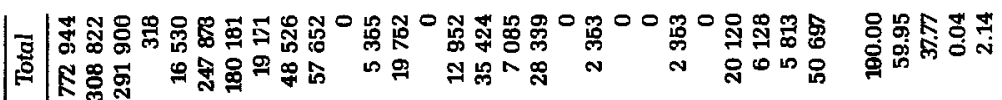

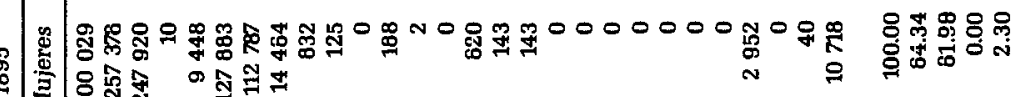

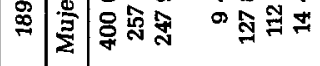

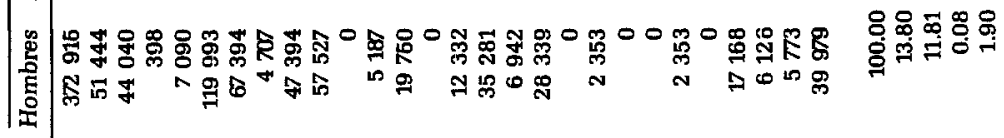

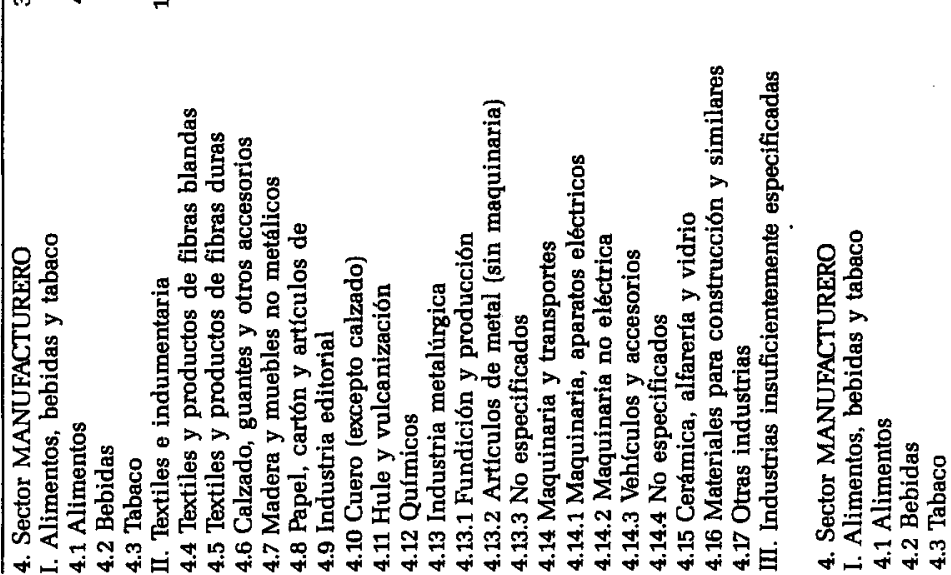




\begin{tabular}{|c|c|c|}
\hline 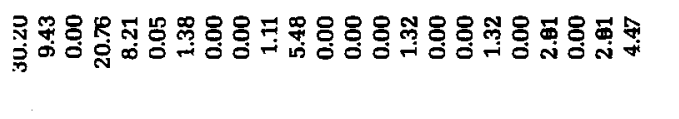 & & 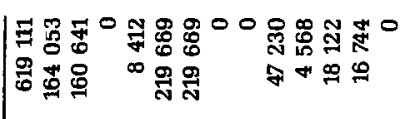 \\
\hline 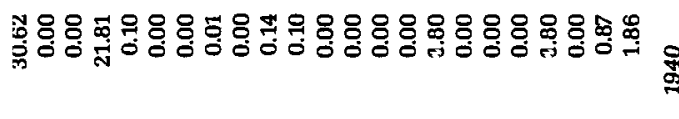 & & 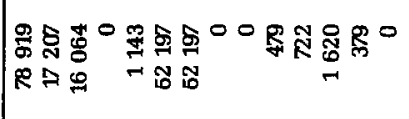 \\
\hline 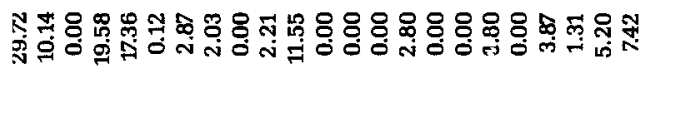 & & 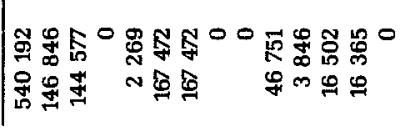 \\
\hline
\end{tabular}

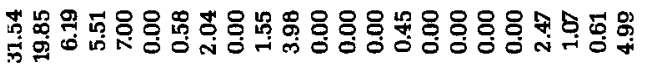

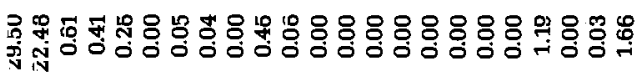

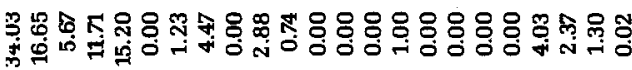
范 要

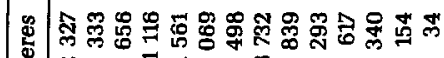
芝 :

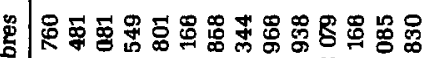

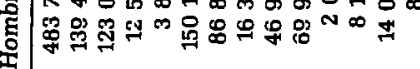

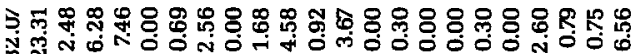

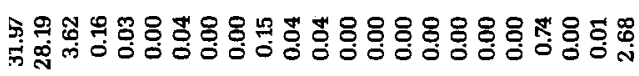

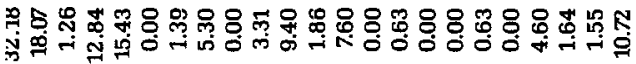

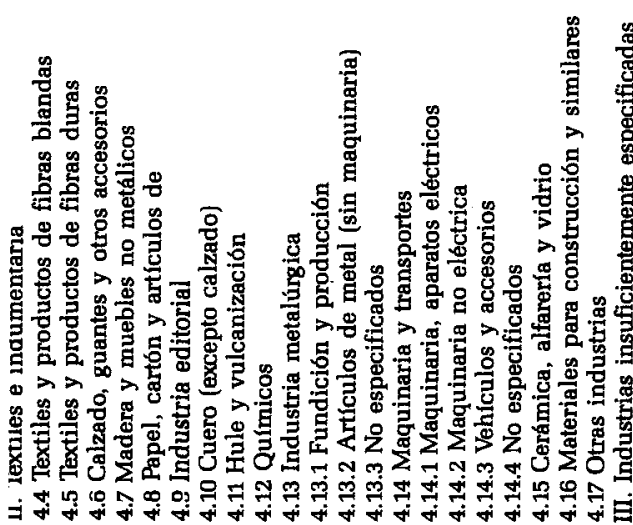

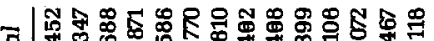

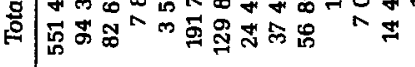
ฐ

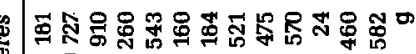
药

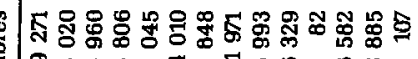

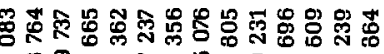

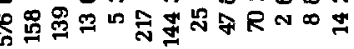

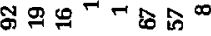


กิ่

要要

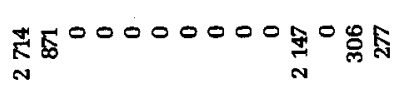

$\exists 000000000 \mathrm{~g}_{0}^{\circ}$

용

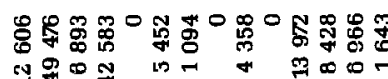

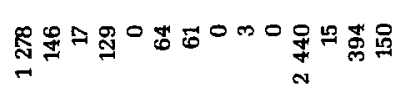

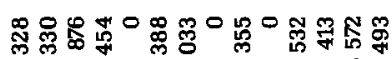

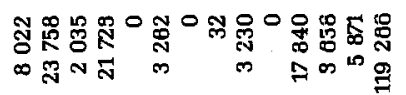

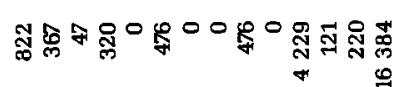

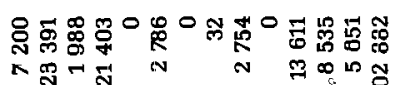

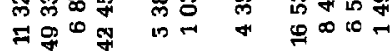

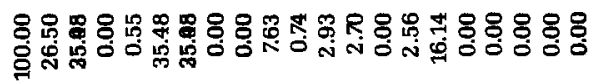

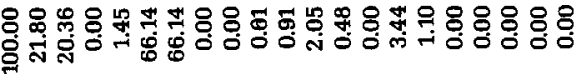

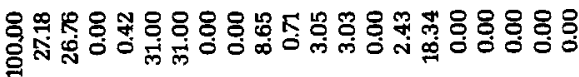

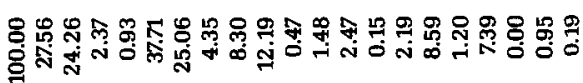

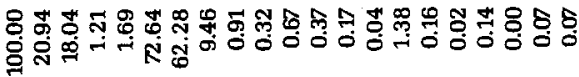

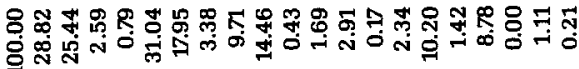

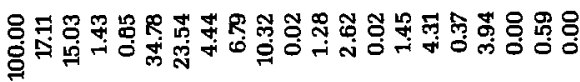

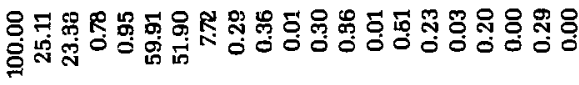

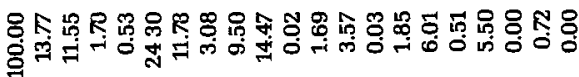

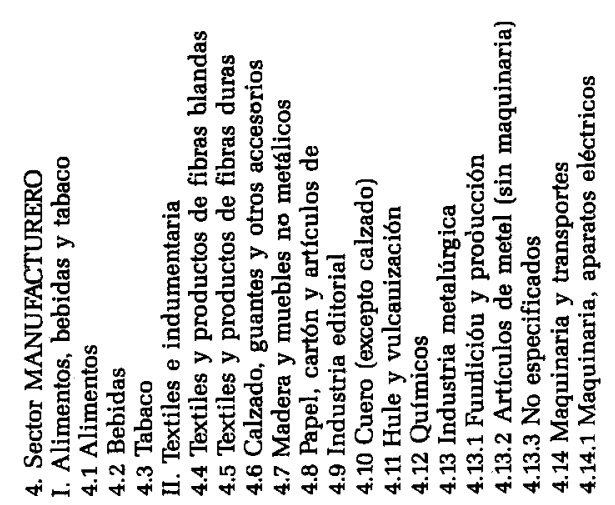




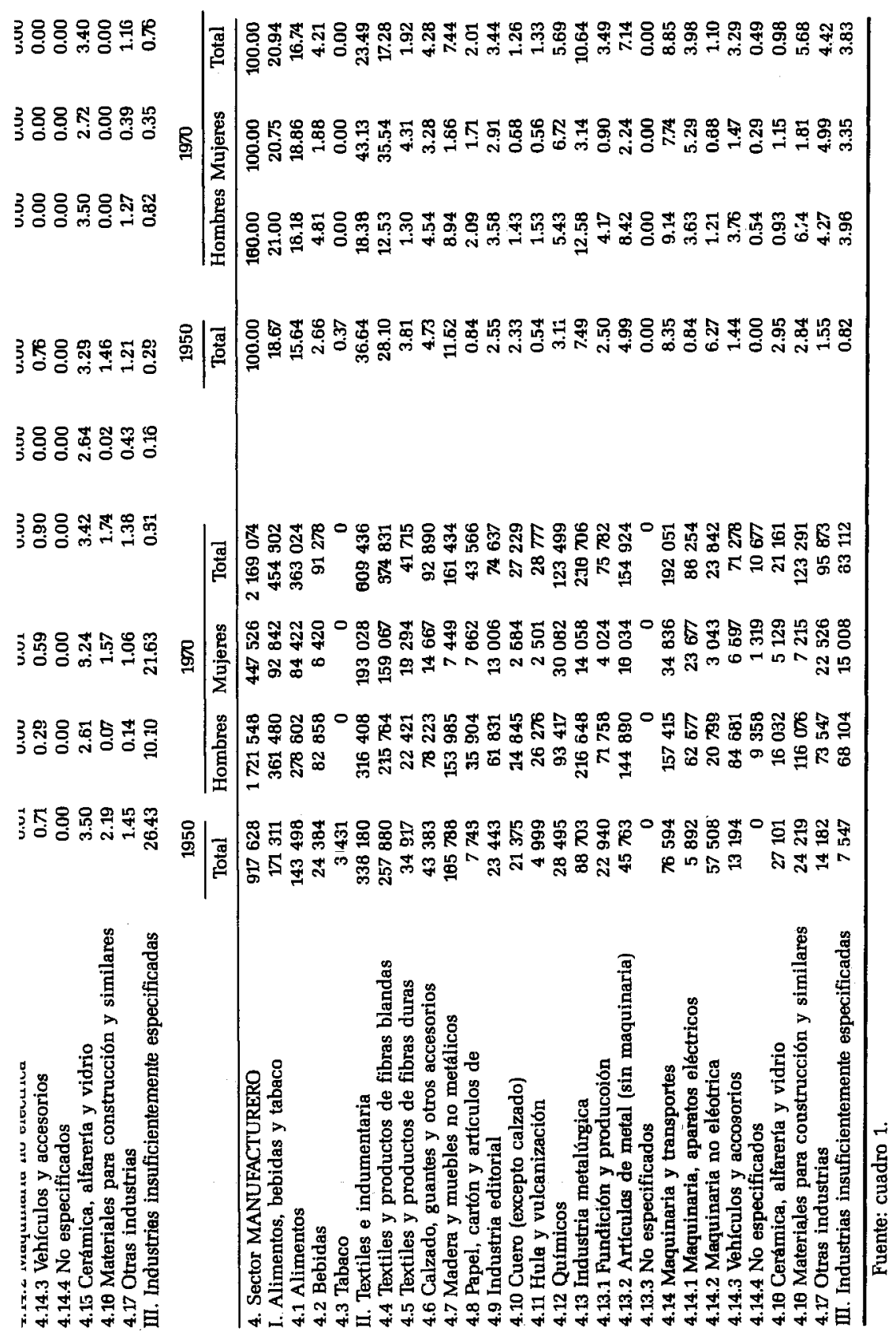




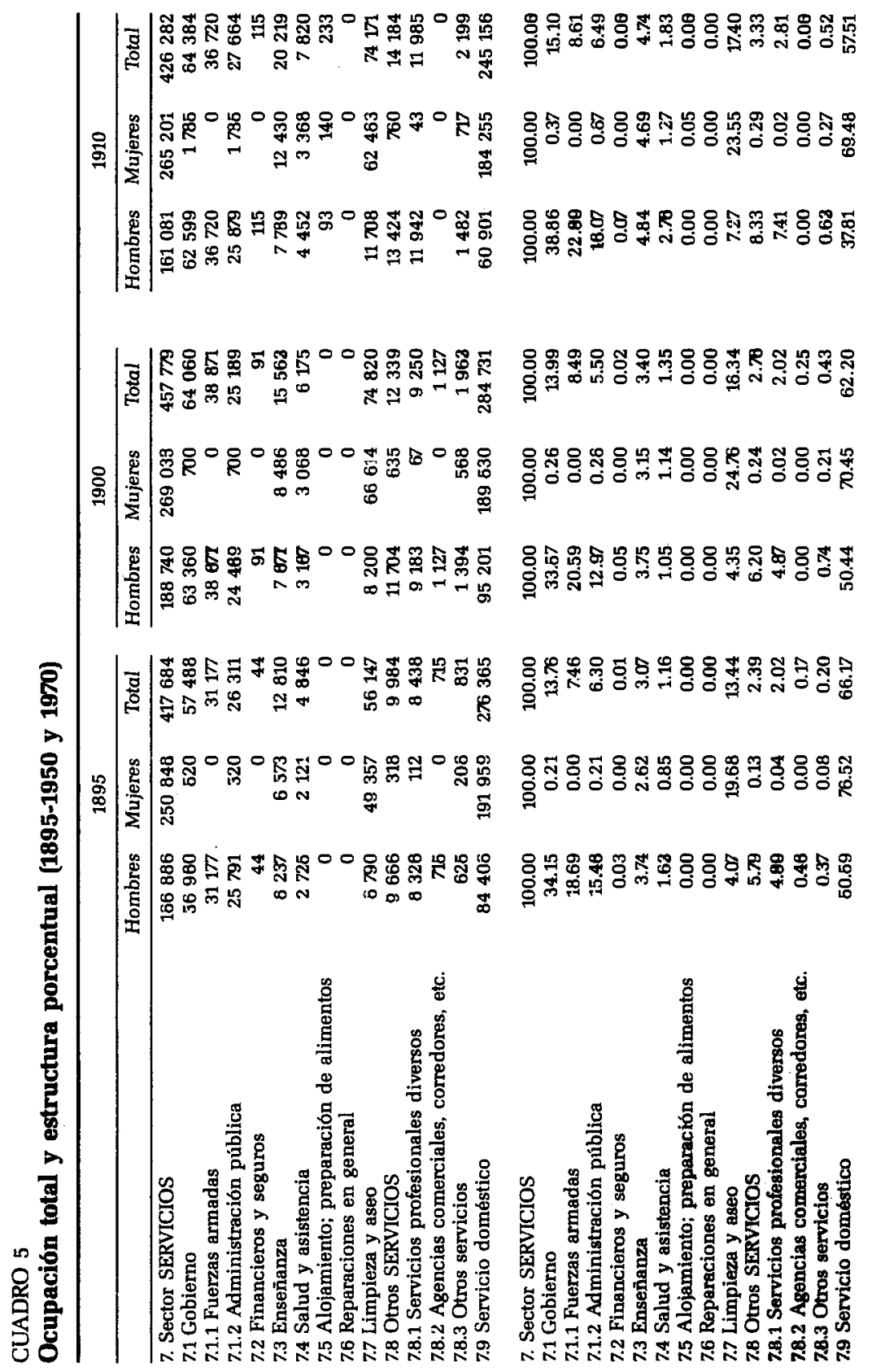




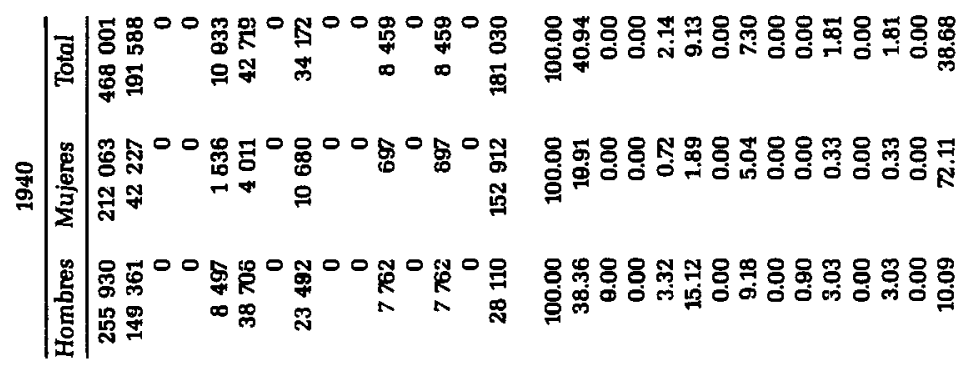

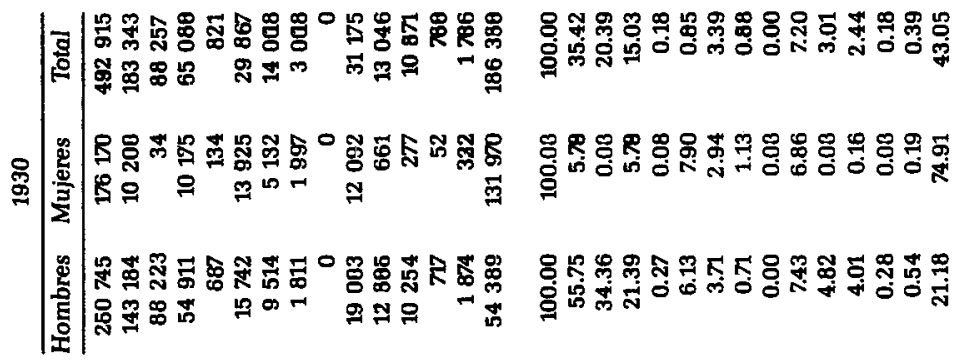

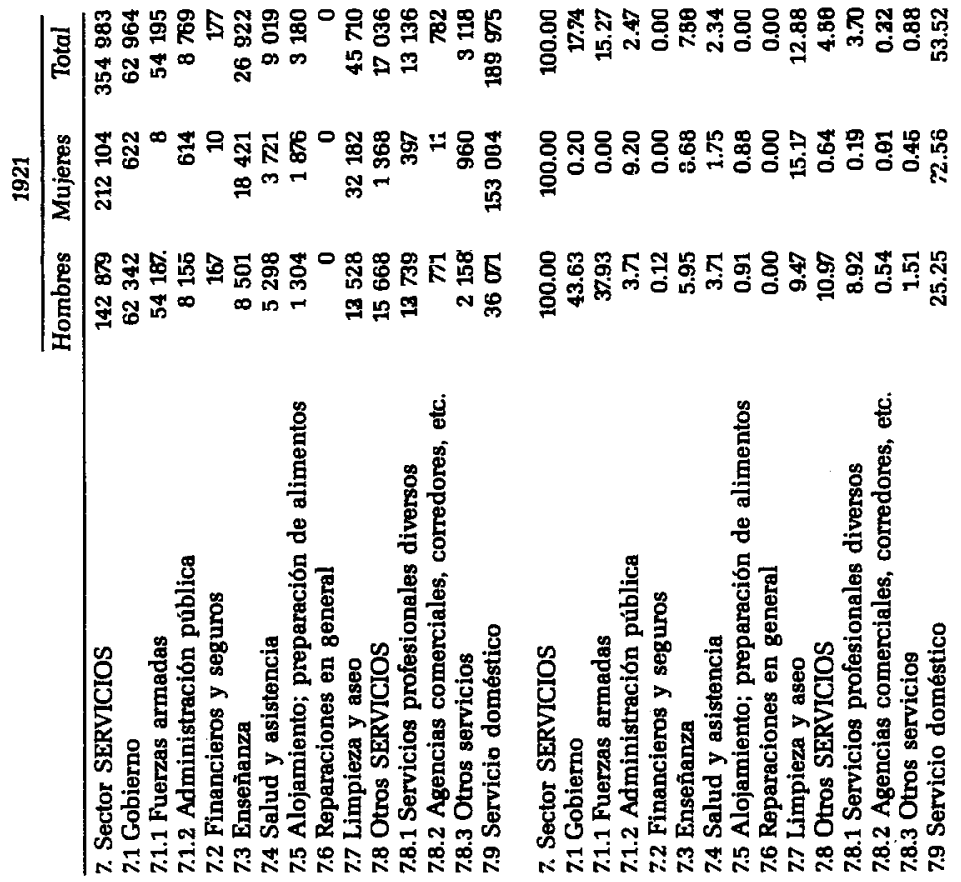




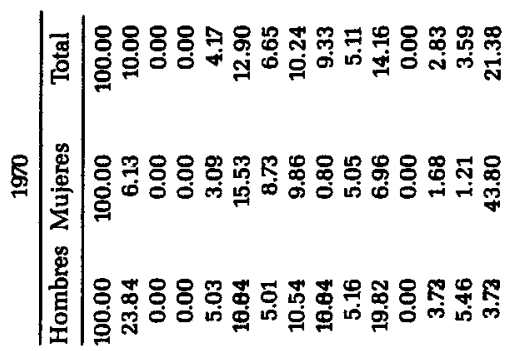

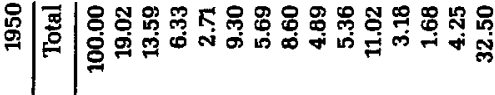

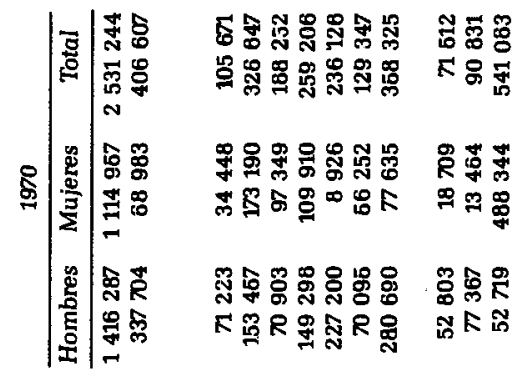

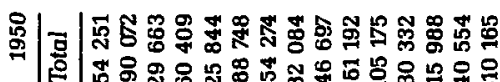

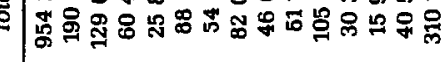

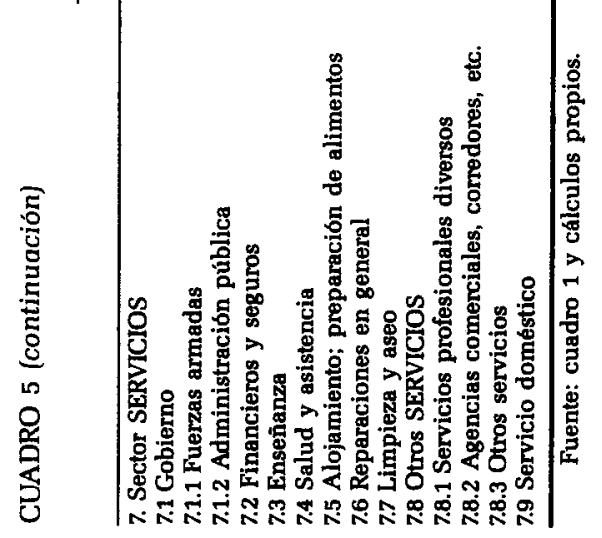


En la configuración de esta estructura agraria fue decisiva la acción del gobierno, mediante sus políticas agraria y de fomento agrícola. Para el campesinado mexicano fue fundamental el reparto agrario, basado sobre todo en la apertura de tierras marginales al cultivo, mientras que la política de fomento (obras de irrigación, crédito, investigación agrícola) se orientó claramente desde los años cuarenta a apoyar el desarrollo del sector empresarial.

Con estas características, el sector agrario sirvió de pilar al desarrollo industrial. Entre 1940 y mediados de los sesenta, la producción agrícola creció a un ritmo suficiente para satisfacer la demanda de alimentos y materias primas; además, las divisas provenientes de las exportaciones agricolas (realizadas sobre todo por el sector capitalista) fueron fundamentales para financiar las importaciones que requería la expansión del aparato industrial. Por otro lado, la economía campesina ha tenido un importante papel en la reproducción del sistema: libera constantemente parte de su fuerza de trabajo, dada su incapacidad para retenerla, ocasionada por su limitado y limitante acceso a medios de producción, lo cual permite mantener bajos los salarios urbanos; pero a la vez retiene en el campo una proporción importante de la población nacional, que la producción capitalista no es capaz de absorber y reproducir.

De 1945 a la primera mitad de los años sesenta los importantes incre-

GRÁFICA 3

PEA y población ocupada en actividades no agropecuarias

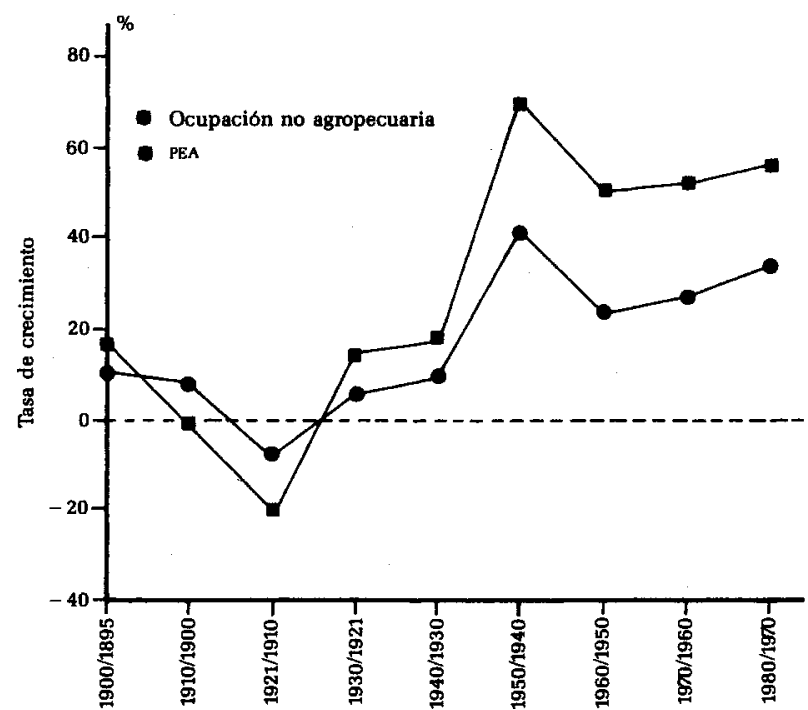


mentos de la superficie agrícola (que permitieron la expansión tanto de la agricultura empresarial como de la economía campesina), el notable aumento en los rendimientos por hectárea de los principales cultivos, producto de la "revolución verde" (que tuvo lugar fundamentalmente en la agricultura capitalista), explican el considerable incremento que registraron tanto la producción como el empleo.

Pero después de 1965 ese dinamismo se perdió y la agricultura dejó de cumplir la mayor parte de las funciones que venía desempeñando. En lo que respecta a la ocupación ya hemos visto que para entonces había alcanzado su límite máximo; a ello contribuyeron varios factores: la superficie agrícola dejó de crecer; en la agricultura capitalista los cultivos que desde principios de los años sesenta mostraron mayor dinamismo (sorgo, cártamo, soya) eran poco intensivos en mano de obra, y en la economía campesina, la parcelación constante de las unidades, la extracción creciente del excedente (cuando lo había o del producto necesario para la reproducción simple), a través de los mecanismos de comercialización y de la relación desfavorable de los precios de sus productos respecto a los bienes industriales, hizo cada vez más difícil la reproducción de las unidades campesinas, lo que determinó la expulsión de proporciones crecientes de fuerza de trabajo.

Esta pérdida de capacidad del conjunto de la agricultura para absorber fuerza de trabajo ocurrió en la etapa en que el crecimiento demográfico había alcanzado su máximo crecimiento; esto impidió que el vasto incremento de la ocupación en el sector no agropecuario se tradujera en un ascenso de la tasa bruta de actividad de la población total. Por el contrario, después de haberse incrementado en 1950 (véase el cuadro 6), recuperó en 1960 su tendencia descendente, pues debido a la importancia relativa de la agricultura en la fuerza de trabajo masculina total, al reducirse el ritmo de crecimiento de la ocupación en ese sector, la tasa bruta de actividad masculina se contrajo. La tasa bruta de actividad femenina, en cambio, se incrementó por la expansión de las actividades terciarias, en las cuales la participación de las mujeres es alta, además de que la importancia relativa del contingente femenino en la fuerza de trabajo ocupada en la industria manufacturera empezó a crecer a partir de 1960.

Si bien el empleo agrícola había dejado de crecer, el auge industrial permitió un crecimiento sostenido del pis durante más de una década y un incremento constante del empleo y del salario en los sectores no agricolas.

Periodo 1970-1980

A principios de los años setenta se presentaron síntomas de una tendencia al estancamiento y pese a los esfuerzos realizados durante la administra- 
CUADRO 6

Tasas brutas de actividad, total y por sexos (1895-1980)

\begin{tabular}{lccr}
\hline & Total & Hombres & Mujeres \\
\hline 1895 & 36.46 & 61.99 & 11.21 \\
1900 & 37.41 & 62.54 & 11.33 \\
1910 & 35.86 & 61.00 & 11.22 \\
1921 & 35.29 & 65.35 & 6.57 \\
1930 & 32.33 & 61.34 & 4.41 \\
1940 & 29.80 & 55.95 & 4.34 \\
1950 & 32.06 & 56.26 & 8.61 \\
1960 & 29.20 & 48.80 & 9.80 \\
1970 & 26.86 & 43.58 & 10.21 \\
1980 & 25.56 & n.d. & n.d. \\
\hline
\end{tabular}

Puente: elaborado a partir de los censos de población.

ción del presidente Echeverría por mantener la expansión económica por medio del gasto público y el endeudamiento, las repercusiones de la crisis mundial de 1974 no pudieron sino postergarse, pues ya en 1975 el producto industrial reducía su ritmo de crecimiento, situación que se agudizó en los dos años siguientes.

En esas circunstancias, la coyuntura favorable del mercado mundial

CUADRO 7

Nuevas ocupaciones por grandes sectores económicos (1921-1950)

\begin{tabular}{lrrrrrr}
\hline & Hombres & $\%$ & Mujeres & $\%$ & \multicolumn{1}{c}{ Total } & $\%$ \\
\hline & & & $1921-1930$ & & & \\
Total & 403552 & 100 & -109847 & 100 & 293705 & 100 \\
Agropecuario & 81601 & 20 & -4965 & 5 & 76636 & 26 \\
Industrial & 152326 & 38 & -67482 & 61 & 84844 & 29 \\
Terciario & 169625 & 42 & -37400 & 34 & 132225 & 45 \\
& & & $1930-1940$ & & & \\
& & & & & & \\
Total & 444592 & 100 & 60848 & 100 & 505440 & 100 \\
Agropecuario & 190362 & 43 & 14231 & 23 & 204593 & 40 \\
Industrial & 102989 & 23 & -29056 & -48 & 73933 & 15 \\
Terciario & 151242 & 34 & 75672 & 125 & 226914 & 45 \\
& & & $1940-1950$ & & & \\
& & & n.d. & & 2413059 & 100 \\
Total & n.d. & & n.d. & & 993030 & 41 \\
Agropecuario & n.d. & n.d. & n.d. & & 519978 & 22 \\
Industrial & n.d. & & n.d. & & 900051 & 37 \\
Terciario & & & & & & \\
\hline
\end{tabular}

Fuente: elaborado a partir de los censos de población. 
CUADRO 8

Participación femenina en la ocupación sectorial 1895-1970 (porcentajes)

\begin{tabular}{lrrrrr}
\hline & 1895 & 1900 & 1910 & 1921 & 1930 \\
\hline Total & 15.47 & 17.04 & 15.64 & 9.50 & 6.90 \\
Agropecuario & 0.37 & 0.84 & 1.74 & 0.86 & 0.71 \\
Transformación & 51.75 & 54.84 & 53.00 & 29.41 & 16.03 \\
Comercio & 20.46 & 20.22 & 20.25 & 16.86 & 14.94 \\
Servicios & 60.05 & 58.76 & 62.21 & 59.75 & 40.69 \\
\hline & 1940 & 1950 & 1960 & \multicolumn{1}{c}{1970} \\
\hline Total & 7.4 & 13.63 & 17.96 & 19.03 \\
Agropecuario & 1.04 & n.d & 10.80 & 5.22 \\
Transformación & 12.74 & n.d & 16.04 & 20.63 \\
Comercio & 17.32 & n.d & 27.00 & 28.31 \\
Servicios & 45.31 & n.d & 50.22 & 44.05 \\
\hline
\end{tabular}

Fuente: elaborado a partir de los censos de población.

del petróleo en los años setenta, que coincidió con una abundancia de recursos crediticios en la banca mundial, permitió a la economía mexicana un auge inusitado que a fin de cuentas no fue sino un paréntesis que sólo logró retardar la tendencia al estancamiento ya manifiesta anteriormente.

El auge 1978-1981, durante el cual el producto y la inversión (entendida en su acepción restringida como la formación bruta de capital fijo) crecieron a una tasa media anual de 8.4 y $16.3 \%$, respectivamente, parece ser el principal responsable del extraordinario incremento que registró la ocupación entre 1970 y 1980 (véase el cuadro 3). ${ }^{10}$

Esto se desprende del hecho de que entre 1970 y 1977 el ritmo de crecimiento de la economía fue considerablemente inferior; la tasa media de incremento anual del piB fue de $5.7 \%$ y la inversión aumentó a $5.1 \%$. Por otra parte, según los censos industrial y de comercio, en estos sectores la tasa de crecimiento de la ocupación que se registró entre 1970 y 1975 fue considerablemente inferior a la que correspondió al quinquenio anterior. En esa década todos los sectores de actividad (exceptuando el agropecuario) registraron incrementos considerables, siendo los más dinámicos el de la construcción y el de servicios; dado su peso relativo en el empleo total, los que más contribuyeron a la generación de nuevas ocupaciones fueron, en orden de importancia, nuevamente el de servicios, el manufacturero y el de la construcción; no obstante, la tasa de crecimiento de la

\footnotetext{
${ }^{10}$ Es muy probable que el ritmo de crecimiento del empleo global y el de algunos sectores esté sobrestimado - aún después de los ajustes hechos a la información censal de 1980. En el examen de los resultados del censo de 1980 encontramos evidencias de sobrestimación y de clasificación errónea de la PEA por rama de actividad. En ausencia de un desglose más detallado de los datos de ocupación para 1980, los ajustes efectuados no pudieron eliminar, del todo, la sobrestimación. Para mayores detalles consúltese Rendón y Salas (1986).
} 
ocupación en las manufacturas se redujo a la mitad en comparación con el decenio anterior (véase el cuadro 3). Esto es atribuible a las tendencias a la modernización, ya manifiestas en el primer lustro de la década, según lo constatan los censos industriales. El efecto de esas tendencias se vio agravado porque en ese quinquenio y en los años siguientes el ritmo de crecimiento de la inversión industrial se incrementó, especialmente en las ramas más dinámicas caracterizadas por una alta composición orgánica de capital, sobre todo la petrolera, y aquellas industrias de transformación que crecieron en forma acelerada como la automotriz y la siderúrgica; en cambio, las industrias tradicionales permanecieron relativamente estancadas. Por otra parte se confirma que, hace ya dos décadas, la agricultura agotó su capacidad de generar nuevas ocupaciones; además, las bajas tasas de crecimiento de la población (atribuibles a un éxodo continuo de sus habitantes) en la mayor parte de los municipios donde predomina la economía campesina, dan cuenta de que el campo no es siquiera capaz de asegurar la reproducción de la población que ahí mora.

Así, entre las ramas productoras de bienes materiales, sólo la construcción registró una capacidad creciente para generar empleos durante el decenio anterior. Este auge tuvo su origen en dos procesos simultáneos: uno es el incremento en el gasto destinado a obras públicas y otro es el aumento en nuevas inversiones de todo tipo realizadas por el sector privado. La creciente incapacidad de las principales ramas vinculadas a la producción material para absorber la oferta potencial de fuerza de trabajo, que se manifestó primero en la agricultura y después en la industria, se vio acompanada, desde los años cincuenta, de una aceleración del proceso de terciarización del empleo. Cabe aclarar que esta incapacidad tendió a concentrarse fundamentalmente en el área de servicios, pues la modernización del comercio, iniciada en los años sesenta, ha empezado ya a manifestar sus efectos sobre el empleo. Los censos comerciales permiten constatar que entre 1960 y 1975 el empleo sectorial sufrió, primero, una pequeña caída en su ritmo de crecimiento y después una abrupta baja. Por otra parte, de los nuevos empleos generados entre 1970 y $1975,35 \%$ correspondió a supermercados y tiendas de autoservicio; a la vez, se registró una disminución en el número de establecimientos y de personal ocupado en la rama de compra-venta de alimentos procesados (integrada sobre todo por tiendas de abarrotes y misceláneas). Estos hechos ilustran claramente los efectos de la modernización del aparato distributivo.

En lo que se refiere al sector servicios, no puede evaluarse cuáles fueron sus ramas más dinámicas porque el censo de población de 1980 no proporciona información detallada. Es de suponer, sin embargo, que se mantuvieron las tendencias observadas entre 1950 y 1970 . El aumento en los gastos sociales destinados a la educación y atención a la salud en la pasada década, hace pensar en un incremento sustancial en ambos rubros de ocupación. A la par de una mayor participación femenina en la 
224

ESTUDIOS DEMOGRÁFICOS Y URBANOS

GRÁFICA 4

Ocupación en manufacturas $(1895=100)$

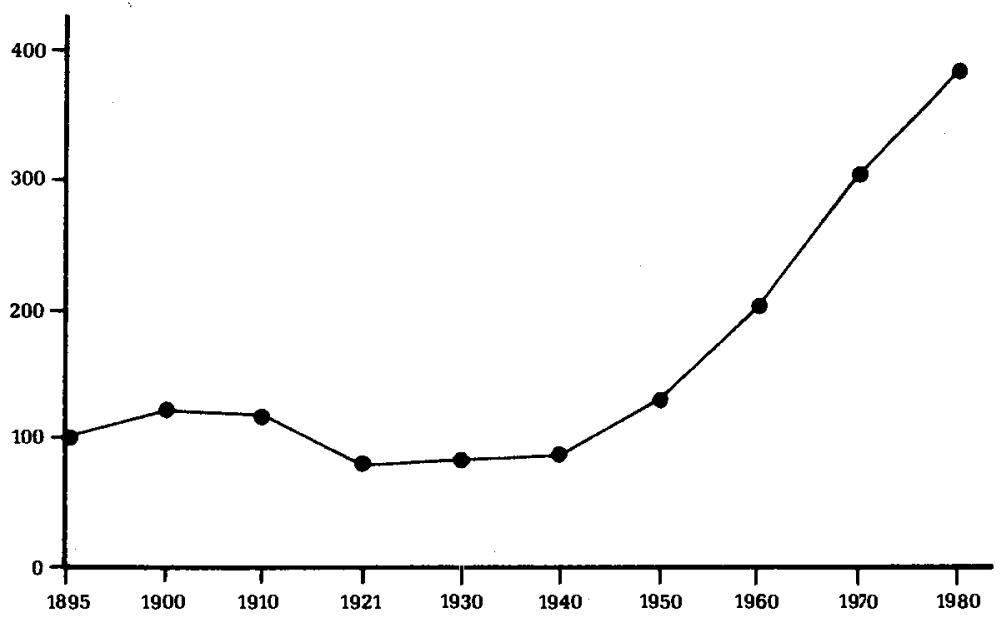

GRÁFICA 5

Ocupación agropecuaria $(1895=100)$

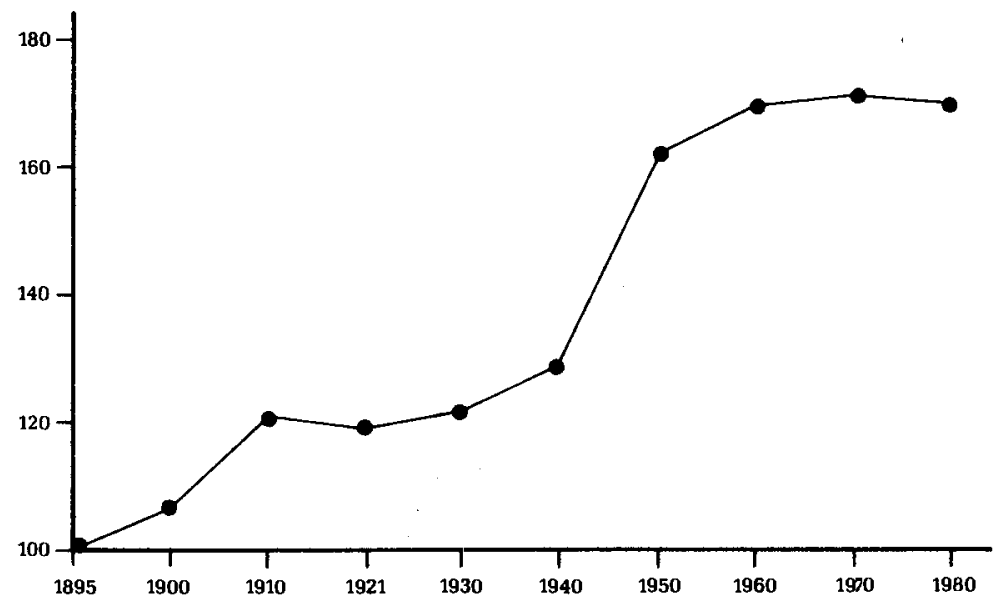




\section{GRÁFICA 6}

Ocupación en el comercio $(\mathbf{1 8 9 5}=\mathbf{1 0 0})$

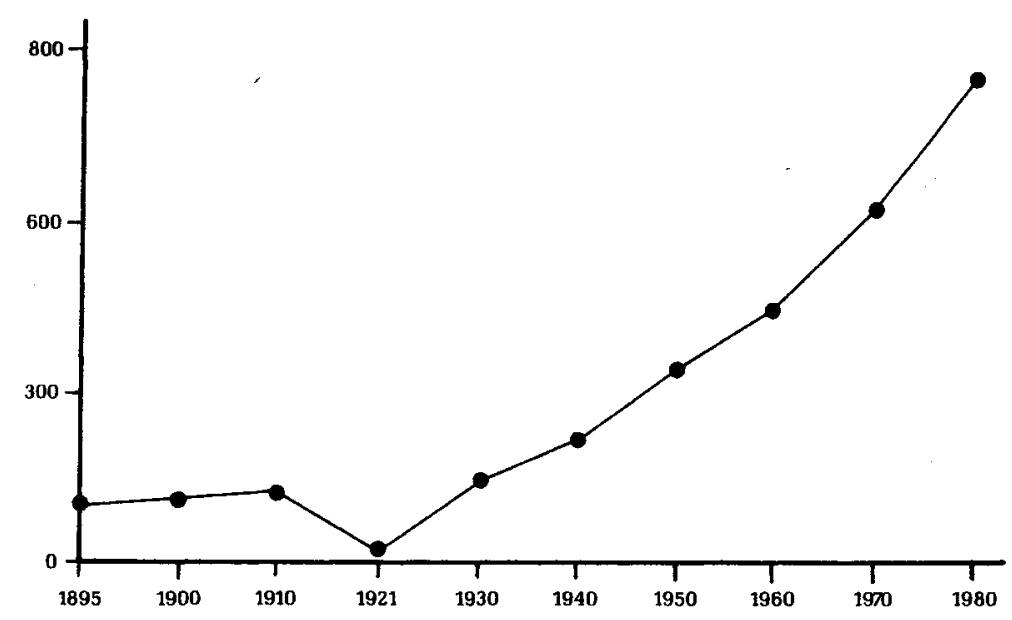

fuerza de trabajo, los servicios de aseo y limpieza, así como los de preparación y venta de alimentos, debieron crecer en forma notable.

El incremento en el número de automotores en la década pasada, así como el consumo de aparatos electrodomésticos, seguramente trajo consigo un aumento en el subsector reparaciones. Cabe señalar que en la mayor parte de los estudios sobre la ocupación en México, la terciarización del empleo suele atribuirse a la incapacidad del sector pära absorber mano de obra, lo que obliga a muchas personas a realizar todo tipo de servicios y actividades por cuenta propia, prescindibles para el funcionamiento de la economía. Se habla, entonces, de la "hinchazón" del terciario, o en términos más en boga, del "sector informal urbano", como una característica privativa de los países llamados subdesarrollados, y se hace caso omiso del papel más importante que, en la generación de ocupaciones terciarias, tiene la expansión del capital hacia actividades comerciales y de servicios, fenómeno que ocurre en todo país capitalista. En el caso de México, las evidencias existentes contradicen la interpretación que postula el acelerado crecimiento de la ocupación en el sector terciario en las dos últimas décadas, como consecuencia del incremento en los servicios personales por cuenta propia y del comercio en pequeño.

Las tendencias sectoriales del empleo que hemos reseñado con base en el análisis empírico indican que la terciarización del empleo no es producto de una "hinchazón" de ese sector, sino del "adelgazamiento" de la ocupación en la agricultura y en la industria. 
Tendencias de la ocupación

En los apartados anteriores presentamos múltiples evidencias de transformaciones sustantivas en la estructura ocupacional del país. Los cambios en la composición sectorial del empleo son el reflejo de las profundas modificaciones que ha sufrido la economía y muestran, además, un proceso caracterizado por grandes tendencias.

Esta sección está dedicada a resaltar los hallazgos más relevantes de nuestro trabajo. La inequívoca presencia de tres grandes etapas (1895-1930, 1930-1970 y 1970-1980) es posiblemente uno de los más significativos. La exístencia de un ciclo largo industrial que culmina en los años treinta ha sido demostrada en la tesis doctoral de Stephen Haber. ${ }^{11}$ Asimismo, los estudios hechos por Jefrey Bortz sobre los salarios industriales en México, los cuales cubren desde 1939 a la fecha, ${ }^{12}$ muestran cómo, durante el periodo de transición entre el modelo de acumulación primario-exportador y el llamado modelo de sustitución de importaciones, los salarios reales cayeran sistemáticamente. A partir de 1954, durante el periodo que llamamos de consolidación del modelo de industrialización, los salarios reales crecieron constantemente. A mediados de la década pasada, los salarios reales iniciaron una brusca caída sin un freno visible en el mediano plazo. Esta caída es resultado del agotamiento del modelo de industrialización.

Pasamos ahora a señalar los rasgos definitorios de los periodos identificados en términos de las características de la ocupación. Como puede apreciarse en la gráfica 8 , durante los tres primeros decenios de este siglo, que marcan el largo proceso de agotamiento del modelo de acumulación basado en el sector primario exportador, el nivel de ocupación se mantuvo prácticamente constante. Durante la primera y la tercera décadas, la tasa de crecimiento medio anual de la fuerza de trabajo era apenas de $0.7 \%$. De hecho, apenas en los años cuarenta, cuando la industria de transformación empezó a perfilarse como el eje del crecimiento (sustituyendo al sector primario-exportador), la ocupación aumentó aceleradamente. Pero sólo hasta que el nuevo modelo de acumulación se consolidó, la senda seguida por la ocupación global pudo determinarse por lo que sucedía en el empleo no agrícola, pues no fue sino hasta entonces que la estructura ocupacional se modificó sustancialmente (véase la gráfica 9 ).

Las gráficas 4 a 8 ilustran claramente la tendencia seguida por la ocupación (tanto global como sectorial) entre 1895 y 1980 . Entre 1895 y 1930 , el sector agropecuario, que hasta los años cincuenta sería la fuente de ocu-

\footnotetext{
${ }^{11}$ Haber (1985) demuestra cómo la columna vertebral de la gran industria en México permaneció intacta a lo largo de la Revolución y cómo, de hecho, sólo después de 1930 la estructura industrial registró cambios significativos.

${ }^{12} \mathrm{El}$ trabajo de Bortz (1977), permite observar la inequívoca existencia de ciclos largos en la retribución a los trabajadores industriales. Por carencia de información adecuada, este tipo de estudios no han sido realizados para otros sectores económicos.
} 
GRÁFICA 7

Ocupazión en servicios $(1895=100)$

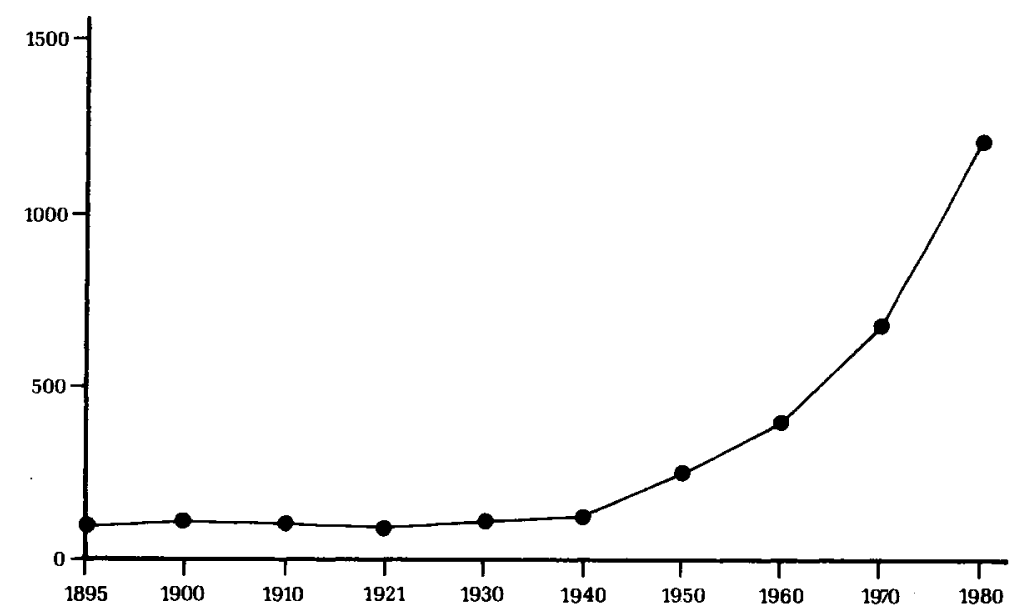

GRÁFICA 8

Ocupacion total

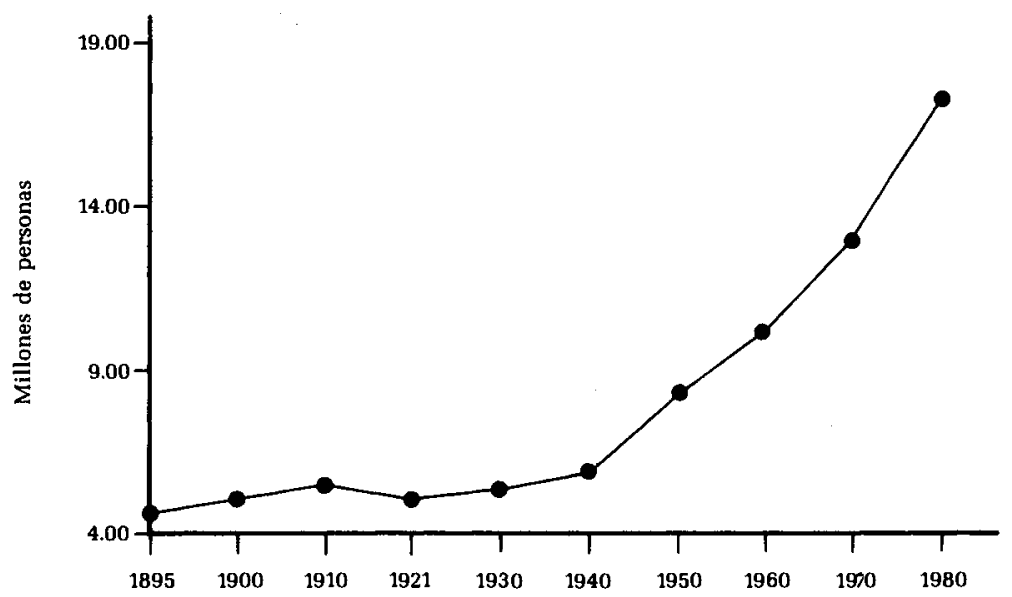




\section{GRAFICA 9}

Ocupación total, agropecuaria y no agropecuaria

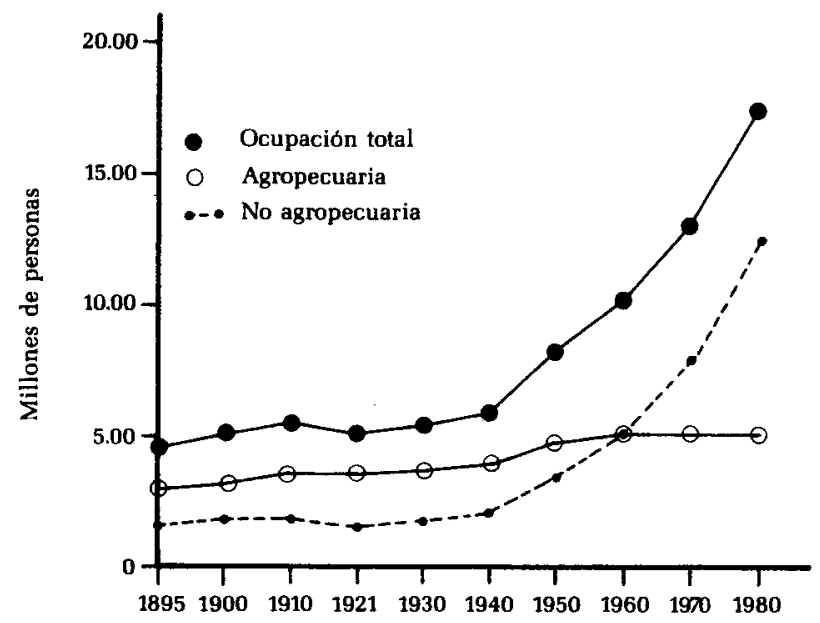

pación de la mayoría de los mexicanos, muestra un crecimiento lento pero continuo, sólo interrumpido durante la Revolución. Pero en la etapa de consolidación de la industria, la fuerza de trabajo agrícola aceleró notablemente su ritmo de crecimiento; esto no hace sino reflejar el importante papel que jugó la agricultura en el proceso de industrialización, en tanto proporcionó abundantes alimentos y divisas al país. A partir de los años sesenta, el empleo agrícola dejó de crecer, reflejando la lenta expansión de la frontera agrícola, el deterioro de las condiciones de reprodución de la economía campesina, además de la mecanización constante y el aumento en la importancia relativa en la agricultura capitalista de cultivos poco intensivos en mano de obra.

La fuerza de trabajo ocupada en la industria de transformación muestra una clara tendencia declinante entre 1900 y 1940, como resultado tanto del lento crecimiento derivado de la estrechez del mercado, como del largo proceso de sustitución de la producción artesanal por la fabril.

A partir de los años cuarenta, el empleo manufacturero se incrementó a un ritmo tal que para 1980 se había triplicado; no obstante, en el último decenio registró una clara tendencia a la desaceleración, a consecuencia, en parte, de un proceso creciente de modernización y concentración. El abatimiento en el ritmo de creación de empleos industriales observado durante los años setenta se debió también al hecho de que la producción 
manufacturera estaba orientada casi exclusivamente al mercado interno, lo cual impuso límites a su expansión. Esto, aunado a la escasez y encarecimiento de las divisas destinadas a la importación de bienes de capital, se tradujo en la crisis que vive la economía mexicana desde 1982. Con esta crisis, se profundiza la manifiesta incapacidad del sistema para generar un número adecuado de ocupaciones, capaz de absorber la fuerza de trabajo disponible. Cuando se comparan las gráficas 6 y 8 , resalta la similitud del comportamiento de la ocupación global y la correspondiente al sector comercio. Tal semejanza parece reflejar cómo la capacidad de expansión de este sector está determinada por el desarrollo de las actividades de producción de bienes materiales. Al observar la gráfica 7 , correspondiente a la ocupación en los servicios, se constata que su expansión se inició cuando la economía se transformó de agraria en industrial. A partir de entonces, el peso relativo del sector dentro del empleo total se incrementó continuamente. En la sección anterior abordamos con cierto detalle este punto; aquí sólo queremos resaltar su capacidad de absorción de fuerza de trabajo y llamar la atención hacia un hecho frecuentemente soslayado en el estudio de este sector: su heterogeneidad. Es muy probable que una buena parte de las opiniones existentes respecto al papel que juega el sector servicios dentro de la economia del país estén basadas en una suposición implícita de homogeneidad dentro de él, supuesto que los datos censales permiten refutar.

Un hecho observable a todo lo largo del siglo (salvo en el decenio de los cuarenta), es el descenso sistemático de la tasa bruta de actividad (véase el cuadro 6). Sin embargo, las causas son diferentes en los distintos periodos. Durante los tres primeros decenios, la explicación principal fue el estancamiento de la actividad económica, que dio como resultado que el aumento de la fuerza de trabajo se situara por debajo del crecimiento demográfico, pese a que éste era lento. En cambio, a partir de los años cincuenta se combinaron dos procesos: la población creció a un ritmo inusitado y la agricultura perdió su capacidad de incorporar nuevos trabajadores.

El monto del crecimiento demográfico ha sido ubicado entre los principales problemas de nuestro pais y uno de los argumentos más socorridos para fundamentar esta opinión es el déficit de puestos de trabajo. ${ }^{13}$ En efecto, la brecha entre el crecimiento de la población y el de la fuerza de trabajo se convierte en un problema para la clase trabajadora pero se manifiesta debido a la presencia de una circunstancia adicional: la mayoría de los trabajadores percibe salarios muy bajos y, en consecuencia, para que una familia pueda subsistir es comúnmente necesario que varios miembros de ésta deban procurarse una ocupación remunerada. En estas circunstancias, se reduce la posibilidad de que los trabajadores puedan lograr aumentos salariales.

\footnotetext{
${ }^{13}$ Un ejemplo son los comentarios que pueden verse en Urquidi y Morelos (1979: 3-8).
} 
México busca hoy redefinir su modelo de crecimiento. Esto parecería implicar nuevos vínculos con el mercado mundial, para lo cual sería necesario orientar una parte importante de las actividades económicas con miras a la exportación. Mientras este proceso no se consolide, la economía nacional difícilmente habrá de manifestar signos de recuperación sostenida. En consecuencia, dada la magnitud de la crisis y las tendencias previas del empleo, es de esperar no sólo el ahondamiento de la brecha entre el crecimiento del empleo y el de la población, sino también un deterioro creciente en las ya de por sí precarias condiciones de vida de las mayorías de nuestro país.

\section{Bibliografia}

Alba, Francisco (1984), La población de México. Evolución y dilemas, El Colegio de México, México.

Bartra, Armando (1976), Notas sobre la cuestión campesina (México 1970-1976), Editorial Macehual, México.

Bortz, Jeffrey (1977), "El salario manufacturero en el D.F., 1939-1974", en Investigación Económica, nueva época, núm. 4.

Haber, Stephen (1985), The Porfirian Industrial Cycle, 1880-1930, tesis de doctorado en el Departamento de Historia de la Universidad de California en los Ángeles.

Keesing, D.E. (1969), "Structural Change Early in Development: Mexico's Changing Industrial and Occupational Structure from 1895 to 1950", en Journal of. Economic History, pp. 716-738.

(1977), "Employment and Lack of Employment in Mexico, 1900-1970", en Wilkie y Ruddle (eds.), Quantitative Latin American Studies, Universidad de California en Los Ângeles, Los Ángeles, Cal., pp. 3-21.

Rendón, Teresa y Carlos Salas (1986), "La población económicamente activa en el censo de 1980. Comentarios críticos y una propuesta de ajuste", en Estudios Demográficos y Urbanos, vol, 1, núm. 2, mayo-agosto de 1986, pp. 291-309.

Reyes Osorio y otros (1974), Estructura agraria y desarmollo agrícola en México, FCE, México, pp. 111-130.

Urquidi, Víctor y José B. Morelos (comps.) (1979), Población y desarrollo en América Latina, El Colegio de México, México. 